Title

\title{
AMPA receptors and Seizures mediate hippocampal radial glia-like stem cell proliferation
}

Running title

AMPARs and radial glia-like stem cells

Authors

Anan Shtaya ${ }^{1,2}$, Ahmed-Ramadan Sadek ${ }^{2}$, Malik Zaben ${ }^{2,4,5,6}$, Gerald Seifert

${ }^{3}$, Ashley Pringle ${ }^{2}$, Christian Steinhäuser ${ }^{3}$ and William Peter Gray ${ }^{2,45,6}$

${ }^{1}$ Neurosciences Research Centre, Molecular and Clinical Sciences Research

Institute, St George's, University of London, London, UK.

${ }^{2}$ University of Southampton School of Medicine

${ }^{3}$ Institute of Cellular Neurosciences, Medical Faculty, University of Bonn.

${ }^{4}$ Institute of Psychological Medicine and Clinical Neurosciences, Cardiff

University

${ }^{5}$ Neuroscience and Mental Health Research Institute, Cardiff University.

${ }^{6}$ B.R.A.I.N. Biomedical Research Unit, Cardiff University.

Corresponding author:

Professor William Peter Gray. Professor of Neurosurgery, Institute of Psychological Medicine and Clinical Neurosciences, Neuroscience and Mental Health Research Institute \& B.R.A.I.N. Biomedical Research Unit, 
Cardiff University, UK GrayWP@cardiff.ac.uk Tel: 02920743798

Fax: 02920744394

Acknowledgements

This study was supported by an FQMS grant to WPG and a Medical Research Council (MRC) strategic grant (G0300356) to WPG.

Total Word count: 6532

Introduction Word count: 789

Materials and methods Word count: 2475

Results Word count: 2084

Discussion Word count: 1184 


\section{Abstract}

Neurogenesis is sustained throughout life in the mammalian brain, supporting hippocampus-dependent learning and memory. Its permanent alteration by status epilepticus (SE) is associated with learning and cognitive impairments. The mechanisms underlying the initiation of altered neurogenesis after SE are not understood. GFAP-positive radial glia (RG) -like cells proliferate early after SE, but their proliferation dynamics and signaling are largely unclear. We have previously reported a polarized distribution of AMPA receptors (AMPARs) on RG-like cells in-vivo and postulated that these may signal their proliferation.

Here, we examined the acute effects of kainate on hippocampal precursor cells in-vitro and in kainate-induced SE on proliferating and quiescent clones of BrdU pre-labelled hippocampal precursors in-vivo.

In-vitro, we found that $5 \mu \mathrm{M}$ kainate shortened the cell cycle time of RG-like cells via AMPAR activation and accelerated cell cycle re-entry of their progeny. It also shifted their fate choice expanding the population of RG-like cells and reducing the population of downstream amplifying neural progenitors. Kainate enhanced the survival of all precursor cell subtypes. Pharmacologically, kainate's proliferative and survival effects were abolished by AMPAR blockade. Functional AMPAR expression was confirmed on RG-like cells invitro. In agreement with these observations, kainate/seizures enhanced the proliferation and expansion predominantly of constitutively cycling RG-like cell 
clones in-vivo. Our results identify AMPARs as key potential players in initiating the proliferation of dentate RG-like cells and unravel a possible receptor target for modifying the radial glia-like cell response to SE.

\section{Keywords}

Kainate; precursors; epilepsy; rat; radial glia-like, AMPARs.

Main Points: (245/250 characters including spaces)

AMPAR activation induces the proliferation, cell cycle re-entry and expansion of hippocampal RG-like stem cells in-vitro and contributes to the expansion of precursor cell populations and subsequent neurogenesis after Status Epilepticus in-vivo. 


\section{Introduction}

The birth of new neurons or neurogenesis in the hippocampal dentate gyrus is sustained throughout life in the vertebrate brain, including humans (Spalding et al., 2013), and has key roles in certain forms of hippocampus-dependent learning and memory (Deng, Aimone, \& Gage, 2010; Gould, Beylin, Tanapat, Reeves, \& Shors, 1999; Shors, 2008; Shors et al., 2001). However, hippocampal neurogenesis is altered by acute seizures and chronic epilepsy (Barkas et al., 2012; Gray, May, \& Sundstrom, 2002; Gray \& Sundstrom, 1998; Hattiangady \& Shetty, 2010; Jessberger, Romer, Babu, \& Kempermann, 2005; Jessberger et al., 2007; Jiruska et al., 2013) quantitatively and qualitatively. These quantitative changes, initially increased neurogenesis (Bengzon et al., 1997; Gray \& Sundstrom, 1998; Parent et al., 1997) and later decreased neurogenesis (Hattiangady, Rao, \& Shetty, 2004; Hattiangady \& Shetty, 2010; Sierra et al., 2015), and qualitative changes (altered synaptic connectivity) (Scharfman, Goodman, \& Sollas, 2000; Shapiro \& Ribak, 2006), are associated with altered hippocampal cognitive function. Conversely, reversal of chronically reduced neurogenesis is associated with the restoration of spatial learning (Barkas et al., 2012). Intraperitoneal injection of the AMPA/kainate receptor agonist kainate, models status epilepticus (SE) (Ben-Ari \& Cossart, 2000) and induces the abnormal formation of new neurons in the hippocampal dentate gyrus that starts immediately after SE and is long lasting (Gray et al., 2002; Gray \& Sundstrom, 1998; Huttmann et al., 2003; Jessberger et al., 2005; Jessberger et al., 
However, the mechanisms, controlling neuronal precursors acutely after SE, are yet to be fully explored.

Under physiological conditions, dentate subgranular zone (SGZ) radial glia-like cells (RG-like cells), proliferate asymmetrically to give amplifying neural progenitors, that further proliferate and commit to a neuronal lineage with terminal differentiation into mature granule cell neurons (Lugert et al., 2010; Morrens, Van Den Broeck, \& Kempermann, 2012; Seri, Garcia-Verdugo, Collado-Morente, McEwen, \& Alvarez-Buylla, 2004; Seri, Garcia-Verdugo, McEwen, \& Alvarez-Buylla, 2001; Steiner et al., 2006). Both RG-like cells and amplifying neural progenitors can alter their pattern of symmetrical or asymmetrical divisions, their cell cycle kinetics as well as their proliferative state (quiescent or cycling). The dynamics of this neurogenic process are not well understood. Interneurons appear to play an important role, with $\mathrm{GABA}_{\mathrm{A}}$ receptors maintaining RG-like cells quiescence (Song et al., 2012) and vasoactive intestinal polypeptide receptor II $\left(\mathrm{VPAC}_{2} \mathrm{R}\right)$ mediating an expansion of the amplifying neural progenitor pool (Zaben et al., 2009). Our research group and others have demonstrated that proliferating RG-like cells are increased in the dentate gyrus (DG) of adult mice, very early after kainateinduced SE (Huttmann et al., 2003; Lugert et al., 2010; Sierra et al., 2015; Steiner, Zurborg, Horster, Fabel, \& Kempermann, 2008), as well as after the onset of spontaneous seizures in non-SE models of epilepsy (Jiruska et al., 
2013; Sierra et al., 2015). However, these studies did not identify the mechanisms or precise patterns by which these RG-like cells are affected by SE. Under physiological conditions, the fine radial processes of dentate RG-like cells ensheath local synapses and vasculature enabling numerous contacts between neurons, astrocytes, microglia and endothelial cells, and therefore likely playing a major role in detecting and channelling the myriad of signals regulating RG-like cell proliferation (Gebara et al., 2016) .

Previous studies have demonstrated AMPARs on RG cells during cortical development (Noctor, Flint, Weissman, Dammerman, \& Kriegstein, 2001; Talos et al., 2006). We have previously demonstrated a polarized distribution of AMPA receptors (AMPARs) on the radial processes but not the soma of adult dentate RG-like cells in-vivo (Renzel et al., 2013). Although this may explain previous paradoxical findings reporting AMPAR expression in adult mouse (Wang, Kempermann, \& Kettenmann, 2005) and absence (Tozuka, Fukuda, Namba, Seki, \& Hisatsune, 2005), their functional significance remains to be determined. As kainate stimulates both kainate and AMPARs, we therefore investigated the direct action of kainate on the different steps of this process invitro, as well as the effects of kainate-induced $\mathrm{SE}$ on quiescent and constitutively proliferating clones of RG-like cells in the SGZ of the adult DG in-vivo. 
Using 5-bromo-2-deoxyuridine (BrdU) and time-lapse video microscopy to follow dividing cells, combined with immunocytochemistry, we found that the chemoconvulsant kainate is specifically proliferative for GFAP-positive RGlike cells, promotes cell cycle re-entry of their progeny and improves survival for all major hippocampal precursor cell subtypes in-vitro. These effects were AMPAR mediated and patch-clamp recordings confirmed the presence of functional AMPARs on GFAP-positive/BLBP positive RG-like cells in-vitro. In-vivo, kainate-induced SE predominantly increased the proliferation and cell cycle re-entry of constitutively dividing clones of GFAP-positive RG-like cells in the SGZ. This was not associated with increased early cell death in the SGZ. These results, in combination with our previous demonstration of functional AMPARs on the radial processes of RG-like cells in-vivo, identify a potentially important role for AMPARs in modulating the proliferation of dentate RG-like cells.

\section{Materials \& Methods}

\section{Cell culture, time-lapse video-microscopy and cell-fate studies}

Cell cultures were generated from Wistar rat hippocampi (P8-10) as described previously (Howell et al., 2003). Two-thirds of growth medium was replaced with fresh medium every 3 days \pm treatment or as specified in each experiment. Time-lapse microscopy was performed on live cell cultures as detailed by us previously (Zaben et al., 2009). The resulting time-lapse movies were then 
carefully studied for mitosis. Each newly born cell was then tracked to determine whether it survived or died. For cell fate studies, cells in culture were staged at $48 \mathrm{~h}$ after plating and contrast phase imaged for $48 \mathrm{~h}$ at hourly intervals. At the end of the time-lapse run, the resulting image stacks were processed to identify divisions where both daughter cells survived. The positions of monitored fields within the tissue culture plates were then converted into coordinates on a reference glass plate of the same footprint as the culture plate and with grid-etched glass coverslips (Bellco Biotechnology) bonded onto it. These positions were relocated on a Leica SP5 laser scanning confocal microscope (Leica DMI600 inverted microscope frame; Leica Microsystems UK Ltd). Cultures were fixed and immunostained and fields were then relocated using the SP5 confocal time lapse microscope and were sequentially scanned with appropriate channels with 3D projections reconstructed using the Zeiss LSM software.

\section{Cell proliferation and cell death}

BrdU (Sigma-Aldrich, UK) and Ki-67 (Novocastra, UK) were used to measure cell proliferation in culture. BrdU was added directly to cells in culture for $6 \mathrm{~h}$ or as indicated to a final concentration of $20 \mu \mathrm{M}$ before cells were rinsed once in Phosphate Buffered Saline (0.1 M PBS) and fixed with 4\% paraformaldehyde (PFA, Sigma-Aldrich, UK) for $20 \mathrm{~min}$ at $4^{\circ} \mathrm{C}$. 
Cell death in culture was quantified using Propidium Iodide (PI; $5 \mu \mathrm{g} / \mathrm{ml}$, Sigma-Aldrich UK), the mitochondrial marker MitoTracker (50 nM) (Life Technologies Ltd, UK) and the nuclear stain DAPI (20 $\mu \mathrm{g} / \mathrm{ml})$ (Sigma-Aldrich, UK). We added PI and DAPI to the cultures $45 \mathrm{~min}$ prior to imaging. MitoTracker was added $30 \mathrm{~min}$ later for $15 \mathrm{~min}$ and without washing, cells were imaged while still alive, before PFA fixation. According to this paradigm, DAPI+, MitoTracker + and PI+ cells are dying cells, DAPI + , PI+ but MitoTracker- cells are dead cells and DAPI+, MitoTracker+ and PI- are live cells.

\section{Immunocytochemistry}

The following primary antibodies were used: rat anti-BrdU 1:200 (Insite Biotechnology, UK), mouse anti-rat nestin 1:200 (BD Biosciences, UK), mouse anti-Glial Fibrillary Acidic Protein (GFAP) 1:200 (Sigma-Aldrich, UK ), rabbit anti-GFAP 1:500 (DAKO, UK), mouse anti-Neuron-specific class III betatubulin (TuJ1) (1:500 Sigma-Aldrich, UK), rabbit anti-TuJ1 1:500 (Cambridge Bioscience Ltd, UK), rabbit anti-GluR2 1:200 (Merck Millipore, UK) a nd rabbit anti-Ki-67 1:500 (Novocastra, UK). Primary antibodies were probed using Cyanin2/Alexa 488, Cyanin3/Alexa 594, or Cyanin5/Alexa 647-conjugated anti-rat 1:500, anti-mouse 1:500 and/or anti-rabbit 1:200 secondary antibodies (Jackson ImmunoResearch, USA) . Cells were then counterstained with DAPI (5 $\mu \mathrm{g} / \mathrm{mL}$, Sigma-Aldrich, UK). For BrdU immunostaining, DNA was first 
denatured by incubating the cells in $2 \mathrm{M} \mathrm{HCl}$ at $37^{\circ} \mathrm{C}$ for $30 \mathrm{~min}$. Omission of primary antibodies revealed no staining.

\section{Patch-Clamp Recording}

Whole cell patch-clamp recordings were performed as detailed previously (Renzel et al., 2013). Recordings were obtained with an EPC9 amplifier (HEKA Electronik, Lambrecht, Germany). Signals were filtered at $3 \mathrm{kHz}$ and sampled at $10 \mathrm{kHz}$. Recording pipettes were fabricated from borosilicate capillaries (Malsfeld, Hilgenberg, Germany). Pipettes for whole-cell recordings had a resistance of 4-6 M $\Omega$ The standard pipette solution consisted of (in $\mathrm{mM}$ ) : 130 $\mathrm{KCl}, 2 \mathrm{MgCl}_{2}, 0.5 \mathrm{CaCl}_{2}, 5$ BAPTA, 10 HEPES and $3 \mathrm{Na}_{2}$-ATP Series resistance and pipette capacitance were compensated for up to $60 \%$ (whole-cell recording). RG-like cells on the culture plates were identified by their typical morphology using an Axioskop FS microscope (Zeiss, Jena, Germany) equipped with a 60X Lum-Plan objective (Olympus, Hamburg, Germany) and a IR/VIS CCD camera VX45 (Optronics, Goleta, CA) .

Drugs for the analyses of AMPARs and $\mathrm{GABA}_{\mathrm{A}} \mathrm{Rs}$ ware applied through the bath perfusion system (Renzel et al., 2013). During application, cells were stepped to potentials between $-130 \mathrm{mV}$ and $+50 \mathrm{mV}(30 \mathrm{mV}$ increment with holding potential of $-70 \mathrm{mV}$ ). Before drug application, $\mathrm{K}^{+}$channels were blocked by adding $\mathrm{BaCl}_{2} \quad\left(\begin{array}{ll}1 & \mathrm{mM}\end{array}\right)$, 4-aminopyridine $\left(\begin{array}{lll}4 & \mathrm{mM}\end{array}\right)$ and tetraethylammonium chloride (TEA, $10 \mathrm{mM}$ ) to the standard recording solution. 


\section{Pharmacology}

To investigate AMPA/kainate receptor-induced effects of kainate on RG-like cells, we applied the competitive antagonist of AMPA and kainate receptors, NBQX (Tocris, UK) at $30 \mu \mathrm{M}$ and the non-competitive AMPAR antagonist, GYKI52466 (Tocris, UK) at $10 \mu \mathrm{M}$.

\section{RT-qPCR and single cell RT-qPCR}

For RT-qPCR, total RNA was extracted from cultured cells (Zaben et al., 2009) and directly reverse-transcribed to cDNA by using SuperScript ${ }^{\mathrm{TM}}$ III Cells Direct cDNA Synthesis Kit (Invitrogen ${ }^{\mathrm{TM}}$ life technologies, Germany). The cDNA was then amplified by one-step PCR kit (custom real-time PCR assay for use with SYBRgreen) (PrimerDesign Ltd, Southampton, UK) in a real-time thermocycler (Rotor-Gene 6000, Corbett Robotics. Ltd). The PCR reaction amplification conditions were: enzyme activation for $10 \mathrm{~min}$ at $95^{\circ} \mathrm{C}$ followed by $15 \mathrm{~s}$ for denaturation at $95^{\circ} \mathrm{C}$ and then the data were collected in $60 \mathrm{~s}$ at $60^{\circ} \mathrm{C}$ AMPA receptor primers were: GluA1; Forward: GATCTGGATGTGTATAGTGTTGC and Reverse: AACTCTTCGCTGTGCCATTC. GluA2; Forward: GTTATGACTCCAGAATTCCCAAAG, Reverse: ACTCAGAAGGTTCCTATCAATCAC. GluA3; Forward: TGAACGAGTACATTGAGCAGAG, Reverse: TTGCCACACCATAGCCTTTG and GluA4; Forward: 
ATtGGTGTCAGTGTGGTCTTG, Reverse: TCATtGGGAGGCTGGTCAC. Reaction amplifications for each product were then run on $2 \%$ agarose gel containing ethidium bromide and visualized using UV light. The uniqueness of the amplicons synthesized were verified by SYBRGreen I dye melting curve analysis.

For single cell RT-qPCR, RG-like cells in-vitro were first identified morphologically using light microscopy, and their cytoplasm was aspirated using RNase-free glass electrodes. Each harvested cell was then lysed using the QuickExtract ${ }^{\mathrm{TM}}$ RNA Extraction Solution. RNA in the cell lysate was reversetranscribed into first-strand cDNA. The reaction was primed by an oligo (dT) primer containing a phage T7 RNA Polymerase promoter sequence at its 5' end. The second-strand cDNA was then synthesized by converting the single-strand cDNA to double-strand cDNA that contains a T7 transcription promoter. Then high yields of amplified RNA were produced in an in-vitro transcription reaction from the double-stranded cDNA template. The amplified RNA was purified by spin-column chromatography. The purified RNA was then reversetranscribed into first-strand cDNA. The reaction was primed using randomsequence hexamer primers. The cDNA produced was diluted for $\mathrm{qPCR}$.

To verify gene expression in these single cells, qPCR reactions were performed with $1 \mu \mathrm{l}$ of the primer mix, $10 \mu \mathrm{l}$ of PrimerDesign $2 \mathrm{X}$ PrecisionTM MasterMix with SYBRgreen and $4 \mu \mathrm{l}$ water to which $25 \mathrm{ng} / \mu \mathrm{l}$ of the indicated cDNA was 
added to a final volume of $20 \mu 1$. Fluorescent data was collected at least once during each cycle of amplification, which allowed for real time monitoring of the amplification. Data was automatically normalized and a threshold was set at the level of maximum amplification during the exponential phase. As soon as the Ct-values were collected, raw data were processed and analyzed using the Comparative Ct method (Schmittgen, 2001) with $2^{-\Delta \Delta \mathrm{Ct}}$ as the comparative expression level. A validation experiment confirmed that different targets were amplified with equal efficiency (Bustin, 2000).

Single-cell RT-PCR after functional characterization. Single-cell RT-PCR of RG-like cells was performed as previously reported (Kunze et al., 2009; Renzel et al., 2013). After recording, the cell at the tip of the pipette was harvested into the pipette in the flow of the bath solution under visual control via a CCD camera (C-5405; Hamamatsu Photonics, Hamamatsu, Japan). The cell was aspirated by applying negative pressure into the recording pipette, and the cell content and $\sim 3 \mu \mathrm{l}$ of the pipette solution was expelled into a reaction tube containing $3 \mu \mathrm{l}$ DEPC-treated water. The reaction tube was frozen and stored at $-20{ }^{\circ} \mathrm{C}$.

The RT mastermix containing first strand buffer (Invitrogen, Darmstadt, Germany), dithiothreitole (DTT, $10 \mathrm{mM})$, dNTPs $(4 \times 250 \mu \mathrm{M}$; Applied Biosystems, Darmstadt, Germany), RNasin ${ }^{\mathrm{TM}}$ (20 U; Promega, Mannheim, Germany), random hexamer primers $(50 \mu \mathrm{M}$; Roche, Mannheim, Germany), 
and reverse transcriptase (SuperscriptIII, $100 \mathrm{U}$, Invitrogen) was added to the frozen cell content in the reaction tube. The reaction $\operatorname{mix}(\sim 10 \mu l)$ was incubated at $37{ }^{\circ} \mathrm{C}$ for $1 \mathrm{~h}$. Concentrations in parentheses represent final concentrations in the respective reaction volumes.

A multiplex two-round single-cell PCR was performed with primers for BLBP (Renzel et al., 2013), GFAP (Renzel et al., 2013), nestin (Table 1) and AMPARs (Matthias et al., 2003). The first PCR was performed after adding PCR buffer, $\mathrm{MgCl}_{2}(2.5 \mathrm{mM})$, primers (200 nM each; for BLBP $100 \mathrm{nM}$ each) and Taq polymerase (5 U; Invitrogen, Darmstadt) to the RT product (final volume $50 \mu \mathrm{l}$ ). Thirty-five cycles were performed (denaturation at $94{ }^{\circ} \mathrm{C}, 25 \mathrm{~s}$; annealing at $51{ }^{\circ} \mathrm{C}, 2 \mathrm{~min}$ for the first 5 cycles, and $45 \mathrm{~s}$ for the remaining cycles; extension at $72{ }^{\circ} \mathrm{C}, 1 \mathrm{~min}$; final elongation at $\left.72{ }^{\circ} \mathrm{C}, 7 \mathrm{~min}\right)$. An aliquot $(2 \mu 1)$ of the PCR product was used as template for the second PCR (35 cycles; annealing at $54{ }^{\circ} \mathrm{C}$, first 5 cycles: 2 min, remaining cycles: 45 s) using nested primers. The conditions were the same as described for the first round, but dNTPs $(4 \times 50 \mu \mathrm{M})$ and Platinum Taq polymerase (2.5 U; Invitrogen, Germany) were added. Products were identified with gel electrophoresis using a low molecular weight DNA ladder (New England Biolabs, Frankfurt, Germany) . As a positive control, RT-PCR for single RG-like cells and for total RNA from mouse brain were run in parallel. Negative controls were performed using 
distilled water or bath solution for RT-PCR. The respective sense and antisense primers are located on different exons to avoid amplification of genomic DNA.

\section{Western blot}

Cells were plated at a density of $10^{6}$ cells $/ \mathrm{mm}^{2}$. Cells were grown for 5DIV in the presence of $5 \mu \mathrm{M}$ kainate or control. On the fifth day $6 \times 10^{6}$ cells from each condition were lysed using CellLyticMT (Sigma-Aldrich, UK) with a protease inhibitor mix (Roche, Switzerland). The sample was left on ice for $30 \mathrm{~min}$ and then centrifuged at $13000 \mathrm{rpm}$ for $20 \mathrm{~min}$ at $-4{ }^{\circ} \mathrm{C}$, the supernatant was then removed. A standard Bradford assay (Bio-Rad, USA) was performed. The appropriate volume of $5 \mathrm{X}$ Lamelli buffer was added to the supernatant. Samples were heated at $100^{\circ} \mathrm{C}$ for $5 \mathrm{~min} .30 \mu \mathrm{g}$ of protein was loaded onto a $12.5 \%$ SDSpolyacrylamide gel and run at $100 \mathrm{~V}$ constant voltage. The gel was blotted onto a nitrocellulose membrane for $2 \mathrm{~h}$ at $25 \mathrm{mV}$ constant voltage. For development the membrane was blocked with 2\% ECL advanced blocking solution in Tris Buffered Saline-Tween $0.1 \%$ for $2 \mathrm{~h}$ and then incubated overnight at $4{ }^{\circ} \mathrm{C}$ with rabbit anti-caspase-3 (Cell Signalling, USA, 1:1000). A secondary anti-rabbit antibody conjugated to horseradish peroxidase was added (Abcam, Cambridge, $\mathrm{UK}, 1: 15,000)$ and incubation for $2 \mathrm{~h}$ was performed. The membrane was developed using the ECL Advanced Western Blotting Detection kit (Amersham Biosciences, UK).

\section{In-vivo experiments}


54 adult male Wistar rats (250-300 g) were used. All our experiments obeyed the 2010 EU Directive, were performed under UK Home Office Regulations, and had the consent of the University of Southampton Bioethics Committee. Rats were housed 6 per cage throughout the experiment and were maintained on a 12:12 h light: dark cycle and provided with unlimited access to food and water for the duration of the experiment.

\section{BrdU and kainate injections, sacrifice and tissue preparation}

A single intraperitoneal (IP) injection of BrdU (50 mg/kg) (Sigma-Aldrich, UK) was given to all rats. This dose of BrdU was intended to label a proliferating clone of cells before kainate induced SE, to allow us to study the clonal kinetics of this subpopulation post SE. $24 \mathrm{~h}$ after the BrdU injections 6 animals were sacrificed forming an un-operated control group. In the remaining 48 animals 24 rats received IP injections of kainate $(10 \mathrm{mg} / \mathrm{kg})$; the other 24 rats were given IP injections of sterile $0.9 \% \mathrm{NaCl}$. Kainate treatment resulted in development of wet dog shakes, head nodding, facial clonus, continued rearing and falling, and generalized tonic-clonic seizures in all rats, 30-60 min after kainate injections. 6 rats per group were then sacrificed $6,24,48$, and $72 \mathrm{~h}$ later, by administration of a terminal dose of phenobarbitone, followed by transcardiac perfusion of $0.9 \%$ $\mathrm{NaCl}$, and of $4 \% \mathrm{PFA}, \mathrm{pH} 7.4$. The whole brains were then post fixed in $4 \%$ PFA. $100(40 \mu \mathrm{m})$ stereologically sampled (every $\left.8^{\text {th }}\right)$ sections per brain, containing hippocampal formation were cut on a Leica VT100M vibrotome. 


\section{Immunohistochemistry}

All immunohistochemistry was performed on systematically sampled tissue, with the initial section selected randomly and subsequent sections being taken at constant intervals (every $8^{\text {th }}$ section) thereafter, ensuring the entire DG was sampled. BrdU and Ki67 labeling was performed on 12 sections per animal. Caspase-3 and doublecortin (Dcx) labellings were performed on 3 sections per animal.

For double stain immunohistochemistry of $\mathrm{BrdU}$ and $\mathrm{Ki} 67$, a citrate $(\mathrm{pH}$ 6.0) microwave pre-treatment was performed. A $2 \mathrm{M} \mathrm{HCl}$ step $\left(37^{\circ} \mathrm{C} ; 30 \mathrm{~min}\right)$ was then performed, followed by incubation with $3 \% \mathrm{H}_{2} \mathrm{O}_{2}-10 \%$ methanol for 30 min and saturation in 2\% horse serum, $3 \%$ goat serum, $0.25 \%$ Triton X-100 (1 h). This was followed by overnight incubation of primary antibodies to BrdU (rat monoclonal 1:1000; Oxford Biotech, UK) and Ki67 (mouse monoclonal 1:50; Novocastra, UK). BrdU was revealed with diaminobenzidine whereas Ki67 was revealed with alkaline phosphatase.

Rabbit polyclonal cleaved caspase-3 primary antibody (1:200 Cell signaling, USA) or anti-goat Dcx primary antibody (1:200 Santa Cruz Biotechnology) were also used. Triple immunohistochemistry studies for BrdU and Ki67 with either Sox2 (1:500 goat polyclonal Santa Cruz, CA, USA) or Dex were also conducted to look at the proliferation of both pre-labeled and un-labeled precursors in SGZ. RG-like cells were immunostained for both mouse anti- 
GFAP (1:500 Sigma-Aldrich, UK) and rabbit anti-BLBP (1:200 Abcam, Cambridge, UK). In addition, triple immunocytochemistry for precursor cells with goat anti-GFAP (1:500, Santa-Cruz, CA, USA), mouse anti-Nestin (1:200, Pharminogen, USA), and rabbit anti-GluR2 (1:200, Invitrogen, USA) was carried out. Secondary antibodies were Alexa 488, Alexa 594, and Alexa 647 (1:500, Invitrogen, USA) raised in donkey and matched all primary combinations.

\section{In-vivo cell quantification}

A blind counting methodology was employed for all quantification. In all groups, BrdU and Ki67 immuno-positive cells were stereologically sampled and exhaustively counted throughout the SGZ and granule cell layer (GCL). The SGZ was defined as a two-nucleus-wide band below the apparent border between the GCL and the hilus (Kempermann et al., 2002). Masks of the SGZ and GCL were generated with the contour tool in StereoInvestigator ${ }^{\mathrm{TM}}$ (Ver. 5.0; Microbrightfield, USA) software package on each DG. Using 20x objective magnification on a Stereology Microscope (Dialux 22, Leitz, GE lighting) cells were then counted in each area using the optical dissector methods. Counts from all sections (every $8^{\text {th }}$ section per brain) in each animal were added, this total was then multiplied by the intersectional interval (8) to calculate a count per DG using Cavalieri’s Principle. 
Because of the difficulties in identifying RG-like cells alone without a reporter construct, it was not feasible to exhaustively count all GFAP + cells with a radial morphology in our stereological samples. So, for determination of the proportional changes between kainate and control conditions of RG-like cells that were Ki67+ or Ki67- and vice versa, we used confocal imaging of cells that were GFAP+ with definite radial process co-localised to a DAPI+ nucleus. We counted $150 \mathrm{Ki} 67+$ SGZ cells from both control and Kainate treated groups at 72 hrs post SE (30 Ki67+ cells per SGZ per animal, from a stereological sample of 5 sections per animal, in 5 animals $=$ total 150 cells) and similarly sampled 152 RG-like GFAP+ cells, and analysed the data using Chi square testing.

\section{Statistical analysis}

For in-vitro experiments, raw data were averaged, plotted \pm standard error of the mean (SEM) and expressed as number of cells per $\mathrm{mm}^{2}$ or percentage. Means were compared using appropriate tests as indicated in figure legends. Statistical significance was set at $\mathrm{p}<0.05$. Data presented in tables in Fig $1 \mathrm{H}$, Fig $2 \mathrm{H}$, Fig $\underline{3 \mathrm{~A}, \mathrm{~B} \& \mathrm{C} \text {, and Fig } 6 \mathrm{~B} \text { are analysed with non-parametric tests. They represent }}$ total numbers from at least 2 different experiments and compared with controls using Chi-square tests. For in-vivo experiments, multiple two-way ANOVA was used to investigate responses to the variables (treatment and time), with 
Bonferroni post hoc comparison. All data are expressed as means \pm SEM per brain (two dentate gyri). 


\section{Results}

\section{Kainate enhances survival of hippocampal precursors through AMPA receptors, over 5 days in vitro.}

Kainate is well known to acutely induce neurogenesis by enhancing proliferation in-vivo (Covolan, Ribeiro, Longo, \& Mello, 2000; Gray et al., 2002; Gray \& Sundstrom, 1998; Nakagawa et al., 2000; Sierra et al., 2015). We aimed to initially characterize its effects in primary hippocampal cell cultures, by analysing the survival and proliferation of different neural precursors.

Overall survival was assessed in-vitro after 5 days of kainate exposure. Kainate significantly enhanced cell survival as indicated by the increase in the proportion of live cells (MitoTracker+PI-DAPI+/DAPI) (63\% vs. 37\% under control conditions) and significantly decreased the percentage of dying cells in culture (MitoTracker+PI+DAPI+/DAPI) from 31\% to $17 \%$ (Fig. 1 A-B) To examine cell phenotype-specific survival effects, cells were co-immunostained for caspase-3 (an apoptotic cell death effector), and either nestin (a precursor marker) or TuJ1 (an immature neuronal marker). Our data shows a significant decrease in the percentage of caspase-3+ cells in the TuJ1 (93\% under control to $73 \%$ under kainate) and nestin ( $82 \%$ vs $65 \%)$ populations. This was confirmed by Western-blot, showing a specific decrease in active caspase-3, compared to unchanged total caspase-3 levels between control and kainate (Fig. $1 \mathrm{G}$ ) .

This trophic effect was further confirmed using time-lapse video microscopy (Fig. $1 \mathrm{H}$ ). In control conditions, out of the 234 cells observed, $84 \%$ $(\mathrm{n}=196)$ 
survived until the end of the experiment (day 5). In contrast, the survival rate after kainate treatment increased to 98\% (279 live cells out of 286 cells).

To determine whether this kainate-survival effect is mediated via kainate and/or AMPARs, cells were again grown for 5DIV in the presence or absence of AMPA or kainate receptor antagonists. Our findings showed that both panAMPAR-kainate receptor (NBQX) and specific AMPAR (GYKI) antagonists abolished the increase in the total number of cells (DAPI + ) after kainate treatment, demonstrating that its survival effect acts through AMPARs (Fig. 1 I).

\section{Kainate stimulates proliferation of hippocampal precursors over the first 3 days in vitro.}

To assess cell proliferation, cells in culture were pulsed for the terminal $6 \mathrm{~h}$ prior to fixation, with the S-phase marker BrdU at $0,1,3,5 \& 7$ days after exposure to $5 \mu \mathrm{M}$ kainate. A significant increase in cell proliferation was not observed until day 3 (29\% vs 17\%) (Fig. 2 A) before it plateaued at day 5 and 7 . These observations suggested that the kainate proliferative effect was temporally specific to one or more cell types in-vitro.

Taken that our hippocampal cell populations in-vitro are largely formed of nestin and/or TuJ1 expressing cells (Zaben et al., 2009), we sought to determine the mitotic index of these cells under kainate treatment. Our results show that kainate increased the mitotic index in the precursor (nestin+) population by a 
similar magnitude, whether the cells were exposed to kainate during 3 days (24\% vs $42 \%)$ or only 6 h on day 3 (26\% vs $41 \%$ ) (Fig. 2 B\&C). However, in the neural progenitor $(\mathrm{TuJ} 1+)$ population, kainate increased the mitotic index (to $26 \%$ from $5.6 \%$ ) o nly when cells were exposed to kainate during 3 days, but not after a short pulse on day 3 (Fig. 2 D\&E). This suggests that the direct proliferative effect is on nestin positive precursors, which then undergo subsequent differentiating divisions to become neuronal progenitors, explaining the cumulative proliferative effect seen on the neuronal progenitor $(\mathrm{TuJ} 1+)$ population after 3 days of kainate treatment.

We then performed growth fraction and labeling index studies to further delineate the proliferative mechanism on nestin-positive precursors. After a short pulse of kainate, the growth fraction (the proportion of cells that expresses both Ki67 and nestin in culture) did not change (Fig. 2 F\&G), implying that kainate did not increase nestin-positive precursor proliferation by recruiting quiescent cells into the cell cycle. Kainate significantly increased the proliferation rate of nestin positive cells, as their labelling index (the proportion of cycling cells entering or in the S-phase of the cell cycle over $6 \mathrm{~h}$ ) increased from $20 \%$ under control conditions to $43 \%$ following kainate treatment (Fig. 2 $\mathrm{H})$.

We can thus conclude that kainate acts by increasing the proliferation rate of nestin-positive precursor cells over the first three days in-vitro. 


\section{Kainate stimulates proliferation of RG-like cells (nestin+ GFAP+), but not amplifying neural progenitors (nestin+ GFAP-) cells at 3DIV.}

Nestin is a microfilament protein that is constitutively expressed by a wide range of precursor cell subtypes ranging from GFAP-positive RG-like cells, to GFAP-negative amplifying neural progenitors cells and early committed neuroblasts which are TuJ1 positive (Steiner et al., 2006). To further investigate the cell sub-types and mechanisms involved in response to kainate, time-lapse experiments were performed to follow dividing cells and identify the phenotype of their progeny by subsequent immunocytochemistry. Because tissue architecture is lost in dissociated culture we defined RG-like precursors as nestin+GFAP + with a uni or bipolar morphology and who exhibited interkinetic nuclear migration during the cell cycle (Noctor, Martinez-Cerdeno, \& Kriegstein, 2008). Although there was a significant overall increase in the number of dividing cells, three days of kainate exposure demonstrated no effect on the proportions of nestin $+\mathrm{TuJ} 1+$ or nestin $+\mathrm{TuJ} 1-$ subpopulations generated (Fig. 3 A). However, kainate significantly increased the proportion of RG-like (nestin+ GFAP+) cells generated, with a reciprocal reduction in non RG-like amplifying neural progenitors precursors (nestin+ GFAP-) (Fig. 3 B), the latter being consistent with previous reports of a reduction in amplifying neural progenitors in-vivo after kainate treatment (Jessberger et al., 2005; Noctor et al., 2008). 
A selective proliferative effect of kainate on type-1 (nestin+/GFAP+) RG-like cells was confirmed using a short terminal $6 \mathrm{~h}$ pulse of BrdU on day three of the time-lapse experiment (Fig. 3 C\&D). Further confirmation of the shortening of the cell cycle time in dividing type-1 (nestin+/GFAP+) RG-like cells was obtained using time-lapse video microscopy (Fig. 3 E), with subsequent GFAP and nestin immunocytochemistry (Fig. 3 F). In this example under kainate conditions, the red-arrowed cell cycle time was $32 \mathrm{~h}$ : the cell divided twice, at 6 $\mathrm{h}$ and $38 \mathrm{~h}$ after the beginning of the time lapse video. In contrast type-1 (nestin+ / GFAP+) RG-like cells did not proliferate more than once, if at all, under control conditions, in the course of $48 \mathrm{~h}$ time-lapse microscopy.

The kainate responsive nestin+/GFAP+ RG-like cells had a bipolar structure and exhibited interkinetic nuclear migration of the cell body along the plane of the radial processes (Fig. 3 E 0-6 h) r eminiscent of the behaviour of prenatal RG cells in the SVZ during cortical development (Noctor et al., 2008). These RGlike GFAP+ cells also stained for the RG marker brain lipid binding protein (BLBP) (Fig. 3 G) .

\section{Kainate-induced proliferation is signalled via AMPARs.}

To clarify the pharmacology of the proliferative effect of kainate on hippocampal precursors, cultured cells were exposed to either AMPA or kainate receptor antagonists. In this set of experiments our data showed that both panAMPA/kainate receptor (NBQX) and specific AMPAR (GYKI) antagonists 
abolished the increase in nestin + and $\mathrm{TuJ} 1+$ cell numbers after kainate treatment (Fig. 4 A\&B). These antagonists also eliminated the increase in the overall mitotic index (Fig. 4 C) and labelling index (Fig. 4 D). These results demonstrated that kainate signals through AMPARs to induce hippocampal precursor cell proliferation. In agreement, a short pulse on day 3 in-vitro of AMPA $(1 \mu \mathrm{M})$, an agonist of AMPARs, mimicked the kainate effects by almost doubling the labelling index in culture (Fig. 4 E).

To validate the action of AMPA on hippocampal precursor cells, the expression of the different AMPAR subunits was analysed by RT-PCR. The results showed that under control conditions hippocampal precursor cell cultures expressed the mRNAs of the 4 GluA subunits of AMPARs, with GluA2 mRNA being the most abundant (Fig. 4 F). GluA2 expression was also confirmed by immunofluorescence in cells expressing GFAP and nestin (RG-like cells, Fig. 4 G) .

We used whole cell patch-clamp recording to verify the presence of functional AMPARs on cells with RG-like cell morphology under kainate conditions invitro. In addition, we harvested cytoplasm from recorded cells and used single cell RT-qPCR, to investigate the expression of GluA1 and GluA2 on RG-like cells $(\mathrm{BLBP}+)$ as GluA2 and probably also GluA1 subunits have been implicated in neural stem cell development (Kapus et al., 2008; Pollard, Heron, 
Moreau, Ben-Ari, \& Khrestchatisky, 1993; Whitney et al., 2008), and their mRNAs were expressed in our whole culture RT-PCR results.

In bath solution containing $\mathrm{K}^{+}$and $\mathrm{Na}^{+}$channel blockers, co-application of kainate $(500 \mu \mathrm{M})$ with the AMPAR modulator cyclothiazide (CTZ, $100 \mu \mathrm{M})$ induced responses with an almost linear $\mathrm{I} / \mathrm{V}$ relation and current reversal close to the predicted value of $0.4 \mathrm{mV}$ (as defined by the Goldman equation). These currents were sensitive to the AMPA/kainate receptor blocker NBQX $(20 \mu \mathrm{M})$ (Fig. $5 \mathrm{~A} \& \mathrm{~B}$ ). Taken together these findings indicate the expression of AMPARs at the cell bodies of type- 1 cells. $\mathrm{GABA}_{\mathrm{A}}$ receptor currents were also recorded from type-1 cells following co-application of muscimol $(100 \mu \mathrm{M})$ and pentobarbital $\left(\begin{array}{ll}50 & \mu \mathrm{M})\end{array}\right)$ (Fig. $\left.5 \mathrm{C}\right)$. Following electrophysiological characterisation, cytoplasmic harvesting and single cell RT-PCR showed coexpression of the RG-like cell markers BLPB and GFAP as well as the GluA2 subunits of AMPARs in the same cells (Fig. 5 D). In total $(n=28), 89 \%$ of the functionally characterized cells expressed BLBP, 39\% expressed nestin and $22 \%$ GFAP. The GluA1 subunit was found in $14 \%$, GluA2 in $39 \%$ of the cells investigated.

Kainate-induced SE increases cycling of constitutively proliferating RGlike cells in the dentate gyrus in-vivo.

We next examined the effects of kainate-induced seizures on morphologically RG-like GFAP-positive cells, in the SGZ of the DG in-vivo. BrdU was injected 
$24 \mathrm{~h}$ before kainate-induced SE to determine if cells were preferentially recruited from this pool of constitutively proliferating cells. We then performed triple labelling with antibodies to BrdU (to identify the progeny of the constitutively dividing population prior to inducing SE), Ki67 (to identify cells proliferating at the time point of sacrifice ( $72 \mathrm{~h}$ after kainate injection) ) and GFAP (to morphologically identify RG-like cells) ( Fig. $6 \mathrm{H}$ ).

We confirmed an increase in cell proliferation in the adult SGZ, $72 \mathrm{~h}$ after SE induction ( $\mathrm{n}=6$ per group) (from 74,752 $\pm 2,849 \mathrm{Ki} 67+$ cells in control conditions to $138,408 \pm 10,010$ after SE, Fig. 6 A). The quantification of proliferating $(\mathrm{Ki} 67+)$ cells shows a significant increase in the proportion of GFAP + RG-like cells in the proliferating population, $72 \mathrm{~h}$ after kainate induced SE, compared to controls $\underline{(21 \%, 32 / 150 \text { cells under control vs } 37 \%, 56 / 150 \text { cells }}$ after SE, Chi square=9.3, p<0.01) (Fig. 6 B). It also shows a significant increase in the proportion of GFAP+ RG-like cells that were proliferating (42\%, 64/152 cells under control vs $76 \%, 115 / 152$ cells after $\mathrm{SE}$, Chi square $=9.2, \mathrm{p}<0.01$ ), thus demonstrating a proliferative recruitment of RG-like cells $72 \mathrm{~h}$ after kainate induced SE, confirming our previous findings (Huttmann et al., 2003).

There was also a significant increase in the number of proliferating (Ki67+) GFAP+ RG-like cells at $72 \mathrm{~h}(17,071 \pm 909$ after SE vs $6,042 \pm 418$ in control animals, Two-way ANOVA with Bonferroni post-hoc test, $\mathrm{p}<0.001$ ) in the SGZ and GCL of the DG. Further analysis shows that the predominant 
contribution to the proliferating cell population after SE was from the RG-like population (6042 cells vs 17,071 cells; Two-way ANOVA with Bonferroni's post-hoc test, $\mathrm{p}<0.001$ ) compared to the non-RG-like population (Fig. $6 \mathrm{C}$ ). The non-RG-like population increase was also significantly different in SE when compared to control (22731 cells vs 29067 cells, Two-way ANOVA with Bonferroni's post-hoc test, $\mathrm{p}=0.04)$, however the predominant increase was in the RG-like population (Fig. 6 C). Within this GFAP+ RG-like population there was a significant increase in the proportion of pre-labelled proliferating RG-like cells (GFAP+ BrdU $+\mathrm{Ki67}+)$ that arose from the constitutively proliferating population (GFAP $+\mathrm{Ki} 67+) \underline{(185 \text { cells, } 2.9 \% \pm 0.3 \% \text { under control }}$ vs 809 cells, $4.4 \% \pm 0.3 \%$ under SE, $\mathrm{p}=0.04$ ) (Fig. $6 \mathrm{D}$ ), showing a preferential proliferation of this population of cells early after SE. Indeed, the increase in BrdU labelled RG-like cells under kainate conditions was more than twice that of the BrdU unlabelled cells (Fig. 6 E). There was no difference in SGZ cell death as indicated by the numbers of activated caspase- 3 positive cells between kainate treated animals and controls (data not shown).

$\underline{\text { To summarise we found that in the proliferating population post SE compared }}$ to control; a greater proportion were proliferating RG-like cells $(12.3 \%$ under $\underline{\text { SE vs } 8 \% \text { under control, } 17,071 \pm 909 \text { cells vs } 6,042 \pm 418 \text { cells) and a greater }}$ proportion of the RG-like cell population was proliferating $(2.9 \% \pm 0.3 \%$ under control vs $4.4 \% \pm 0.3 \%$ under SE, $\mathrm{p}=0.04)$. 
As there was no difference in the number of BrdU+ cells labelled at $6 \mathrm{~h}$ post BrdU injection $(12,855 \pm 4,208$ in control vs $15,527 \pm 3,093$ after SE) (Fig. 6 F), with a subsequent significant increase by $72 \mathrm{~h}(16,023 \pm 3,974$ in control vs $49,427 \pm 8,352$ post SE) (Fig. $6 \mathrm{~F}$ ), together with the preferential origin of the proliferating GFAP+ RG-like cells from the BrdU-labelled clone, implies that kainate-induced SE shortened the cell cycle time and increased cell-cycle reentry, as the number of BrdU + cells quadrupled after SE compared to a $25 \%$ increase under control conditions, as well showing a preferential effect on constitutively proliferating RG-like cells within $72 \mathrm{~h}$ post SE.

To further validate that proliferating GFAP + cells with a RG morphology were precursor cells, we co-immunostained them for Sox 2 expression (a precursor cell marker (Hattiangady \& Shetty, 2008)), GFAP and Ki67. We found a significant increase $(4,604 \pm 318$ under control vs $12,919 \pm 688$ post SE) in the numbers of proliferating RG-like (GFAP+, Sox2+, Ki67+) cells) at $72 \mathrm{~h}$ after kainate-induced SE (Fig. 6 G) .

In conclusion, our results confirm a proliferative action of kainate-induced SE on GFAP+ RG-like cells in-vivo, and further show a preferential effect on the constitutively proliferating subpopulation of these cells.

\section{Discussion}

The abnormal generation of new neurons after SE is well described (Bengzon et al., 1997; Gray et al., 2002; Gray \& Sundstrom, 1998; Parent et al., 1997), as is 
their integration into abnormal circuitry and potential for long-term survival (Jessberger et al., 2007; Scharfman et al., 2000). Although much work has clarified the types of precursor cells affected by SE (Huttmann et al., 2003; Sierra et al., 2015; Steiner et al., 2006) the molecular mechanisms involved in the early control and regulation of precursor cells and their fate in the epileptic brain are challenging and yet to be clarified. While a variety of neurotransmitters including GABA (Song et al., 2012), neuropeptides (Howell et al., 2005; Howell et al., 2007) serotonin (Barkas et al., 2012), dopamine (Xing, Esau, \& Trudeau, 2015) and acetylcholine (Kita et al., 2014) affect neurogenesis, the role and signalling of RG-like cells in the process is unclear. While GABA has been shown to promote quiescence of these cells in the SGZ mediated via the $\mathrm{GABA}_{\mathrm{A}}$ receptor (Song et al., 2012) little is known about how their proliferation is signalled (Liu, Wang, Haydar, \& Bordey, 2005). D-serine, an NMDA receptor co-agonist slightly increases the proliferation of RG-like cells (Sultan, Gebara, Moullec, \& Toni, 2013), but only after prolonged and not acute exposure (Huang et al., 2012), implying an indirect effect via altered neutral activity.

Here we show that kainate, acting via AMPARs increases the proliferation rate and cell cycle re-entry of post-natal RG-like cells in-vitro. These cells had a unibipolar morphology as seen in RG cell culture (Gasser \& Hatten, 1990), stained for GFAP and nestin as well as BLBP and exhibited interkinetic nuclear 
migration on time-lapse video microscopy, confirming both morphological, immunostaining and cell kinetic characteristics typical of RG cells during embryonic development (Kriegstein \& Alvarez-Buylla, 2009; Noctor et al., 2001). We further show that these cells contain functional AMPA and $\mathrm{GABA}_{\mathrm{A}}$ receptors, in agreement with previous reports of AMPARs on SGZ RG-like cells in adult DG in-vivo (Renzel et al., 2013; Wang et al., 2005). These findings are consistent with the demonstration of ionotropic glutamate receptors on uncommitted neural precursor cells during cortical development (Gallo, Pende, Scherer, Molne, \& Wright, 1995) and specifically on RG-like cells (Lopez, Lopez-Colome, \& Ortega, 1994). From a functional perspective, our findings of both positive survival and proliferative effects of AMPAR stimulation on RG-like cells is also consistent with that found on precursor cells in the embryonic ventricular zone (Haydar, Wang, Schwartz, \& Rakic, 2000) and adult subventricular zone (SVZ) (Brazel, Nunez, Yang, \& Levison, 2005). Consistent with this, our RG-like cells exhibited interkinetic nuclear migration, which is a characteristic of ventricular zone RG but not SVZ precursors (Rakic \& Sidman, 1973). Interestingly our RG-like cells expressed the GluA2 subunit of the AMPARs, implying that these AMPA receptors are only weakly $\mathrm{Ca}^{++}$ permeable, another feature shared with adult SGZ RG-like cells in-vivo (Renzel et al., 2013). Our cultured RG-like cells also expressed functional $\mathrm{GABA}_{\mathrm{A}}$ receptors in common with adult SGZ RG-like cells but did not demonstrate the 
adult polarized distribution of AMPARs, implying either a developmental polarization of these receptors after the postnatal period or the dependence of polarization on a 3D niche and/or functional circuitry of the SGZ, and hence their absence in our 2D culture. Recent studies (Gebara et al., 2016; Moss et al., 2016) identified a type $\alpha$ RG-like cell as the proliferative stem cell of the dentate neurogenic niche in mice and despite the species differences, it is likely that our rat derived culture system preferentially selected for these cell types as the primary tissue was taken in the postnatal period when neurogenesis peaks. Despite our inability to comprehensively characterise our RG-like cells morphologically with just GFAP and Sox2 staining in-vivo, these $\alpha$ cells are also likely to have largely contributed to the kainate induced SE response invivo, as the constitutive proliferating clone of RG-like cells was the predominant contributor to the post-SE response. Clearly, not all the prelabelled clones were recruited into the response, which is again consistent with the transition of type $\alpha$ cells into non-proliferative type $\beta$ cells with astrocytic terminal differentiation after SE (Sierra et al., 2015). Indeed, our prior demonstration of a low number of BrdU labelled type $\beta$ S100ß+RG-like cells in the dentate SGZ after SE (Huttmann et al., 2003) is consistent with this hypothesis.

The radial processes of RG-like cells travel through the densely packed granule cells in-vivo, and receptors expressed along these processes would seem to be 
perfectly located for sensing neuronally released glutamate (Moss et al., 2016). However, the functional demonstration of AMPAR-mediated proliferation of RG-like cells in-vivo awaits future experimentation. Nevertheless, our demonstration of a proliferative and a positive survival response to AMPAR stimulation in-vitro supports this functional hypothesis, as does the recent demonstration that chronic treatment with the AMPAR potentiator Org 26576 increases neuronal cell proliferation and survival in adult rodent hippocampus (Su et al., 2009a).

Our in-vitro experiments demonstrated that AMPA or kainate exposure shortened the cell cycle time of RG-like cells and promoted cell cycle re-entry. We found evidence to support a similar pattern of response by RG-like cells invivo after kainate-induced SE. Unlike the in-vitro findings, there was evidence of recruitment of RG-like cells into the cell cycle by $72 \mathrm{~h}$ post SE as the proportion of all proliferating cells that expressed a radial morphology and immunostained for GFAP was increased. Interestingly both the number and proportion of proliferating RG-like cells that were pre-labelled with BrdU were significantly increased $72 \mathrm{~h}$ after SE. Given the identical numbers of BrdU labelled cells in the SGZ between control and post SE conditions at $6 \mathrm{~h}$, and 24 $\mathrm{h}$ (data not shown) these findings are consistent with shorting of the cell cycle of pre-labelled RG-like cells with subsequent cell cycle re-entry. Indeed the proportional increase in BrdU pre-labelled Ki67-positive RG-like cells of 
approximately $33 \%$ suggests a combination of both symmetrical and asymmetrical divisions in the absence of increased cell death. Interestingly, Sierra et al showed that after high doses of kainate in-vivo, RG-like cells are more likely to divide symmetrically into reactive astrocytes possibly via type $\beta$ cells. The high doses of kainate we used in our postnatal cultures may thus have eventually pushed type $\alpha$ cells towards a $\beta$ phenotype, a hypothesis for future experimental investigation. As we did not use reporter gene constructs to identify and follow our RG-like cell population in-vivo, we cannot confirm Sierra et al.'s (2015) findings, but consider it highly likely.

We did not further investigate the molecular mechanisms by which kainate regulates cell proliferation as it was outside the scope of the present study. Neurotransmitters can regulate cell proliferation and fate specification prior to the formation of synaptic connections. Although AMPA receptor activation has been shown to increase cell proliferation in the adult rat hippocampus and

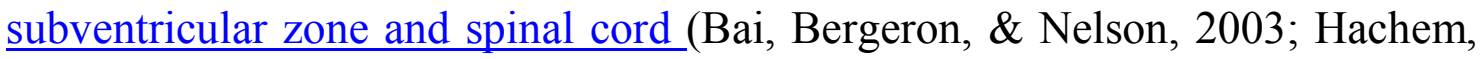
Mothe, \& Tator, 2017; Schitine et al., 2012; Su et al., 2009b) the precise signalling mechanisms remain unclear. Interestingly, a novel AMPA antagonist has recently been shown to inhibit human leukaemia Jurkat $\mathrm{T}$ cell proliferation by arresting the G2/M phase transition (Parenti et al., 2016). However, AMPA/kainate receptor activation has also been shown to decrease retinal progenitor proliferation by increasing cell cycle exit (Martins, Linden, \& Dyer, 
2006)_suggesting a complex regulation whereby stem/precursor cell AMPA receptors can positively or negatively regulate proliferation, at different cell cycle points $(\mathrm{G} 1 / \mathrm{S}$ and $\mathrm{G} 2 / \mathrm{M})$ and in a cell-type specific context.

In conclusion, our results demonstrate that kainate favoured the proliferation and survival of RG-like cells via AMPAR activation. After kainate/SE, RG-like cells re-enter the cell cycle, which becomes shortened. Both symmetric and asymmetric RG-like cell proliferation after $\mathrm{SE}$ in-vivo contribute to the expansion of precursor cell populations and neurogenesis. Further work is required to confirm the functional role of AMPAR signalling on RG-like cells in-vivo after SE, which may identify them as novel targets for antiepileptic therapies and other pathological conditions where the RG-like population of cells is prematurely exhausted. This work may also have eventual relevance for strategies to prevent cognitive decline with increasing age. 


\section{References}

Bai, F., Bergeron, M., \& Nelson, D. L. (2003). Chronic AMPA receptor potentiator (LY451646) treatment increases cell proliferation in adult rat hippocampus. Neuropharmacology, 44(8), 1013-1021. doi:S0028390803001047 [pii]

Barkas, L., Redhead, E., Taylor, M., Shtaya, A., Hamilton, D. A., \& Gray, W. P. (2012). Fluoxetine restores spatial learning but not accelerated forgetting in mesial temporal lobe epilepsy. Brain, 135(Pt 8), 2358-2374. doi:10.1093/brain/aws176

Ben-Ari, Y., \& Cossart, R. (2000). Kainate, a double agent that generates seizures: two decades of progress. Trends Neurosci, 23(11), 580-587. doi:S0166-2236(00)01659-3 [pii]

Bengzon, J., Kokaia, Z., Elmer, E., Nanobashvili, A., Kokaia, M., \& Lindvall, O. (1997). Apoptosis and proliferation of dentate gyrus neurons after single and intermittent limbic seizures. Proc Natl Acad Sci U S A, 94(19), 10432-10437.

Brazel, C. Y., Nunez, J. L., Yang, Z., \& Levison, S. W. (2005). Glutamate enhances survival and proliferation of neural progenitors derived from the subventricular zone. Neuroscience, 131(1), 55-65. doi:10.1016/j.neuroscience.2004.10.038

Bustin, S. A. (2000). Absolute quantification of mRNA using real-time reverse transcription polymerase chain reaction assays. J Mol Endocrinol, 25(2), 169-193. doi:JME00927 [pii]

Covolan, L., Ribeiro, L. T., Longo, B. M., \& Mello, L. E. (2000). Cell damage and neurogenesis in the dentate granule cell layer of adult rats after pilocarpine- or kainate-induced status epilepticus. Hippocampus, 10(2), 169-180. doi:10.1002/(SICI)10981063(2000)10:2<169::AID-HIPO6>3.0.CO;2-W

Deng, W., Aimone, J. B., \& Gage, F. H. (2010). New neurons and new memories: how does adult hippocampal neurogenesis affect learning and memory? Nat Rev Neurosci, 11(5), 339-350. doi:nrn2822 [pii]

$10.1038 / \mathrm{nrn} 2822$

Gallo, V., Pende, M., Scherer, S., Molne, M., \& Wright, P. (1995). Expression and regulation of kainate and AMPA receptors in uncommitted and committed neural progenitors. Neurochem Res, 20(5), 549-560.

Gasser, U. E., \& Hatten, M. E. (1990). Neuron-glia interactions of rat hippocampal cells in vitro: glial-guided neuronal migration and neuronal regulation of glial differentiation. J Neurosci, 10(4), 1276-1285.

Gebara, E., Bonaguidi, M. A., Beckervordersandforth, R., Sultan, S., Udry, F., Gijs, P. J., . . . Toni, N. (2016). Heterogeneity of Radial Glia-Like Cells in the Adult Hippocampus. Stem Cells, 34(4), 997-1010. doi:10.1002/stem.2266

Gould, E., Beylin, A., Tanapat, P., Reeves, A., \& Shors, T. J. (1999). Learning enhances adult neurogenesis in the hippocampal formation. Nat Neurosci, 2(3), 260-265. doi:10.1038/6365

Gray, W. P., May, K., \& Sundstrom, L. E. (2002). Seizure induced dentate neurogenesis does not diminish with age in rats. Neurosci Lett, 330(3), 235-238.

Gray, W. P., \& Sundstrom, L. E. (1998). Kainic acid increases the proliferation of granule cell progenitors in the dentate gyrus of the adult rat. Brain Res, 790(1-2), 52-59.

Hachem, L. D., Mothe, A. J., \& Tator, C. H. (2017). Positive Modulation of AMPA Receptors Promotes Survival and Proliferation of Neural Stem/Progenitor Cells from the Adult Rat Spinal Cord. Stem Cells Dev, 26(23), 1675-1681. doi:10.1089/scd.2017.0182

Hattiangady, B., Rao, M. S., \& Shetty, A. K. (2004). Chronic temporal lobe epilepsy is associated with severely declined dentate neurogenesis in the adult hippocampus. Neurobiol Dis, 17(3), 473-490. doi:10.1016/j.nbd.2004.08.008

Hattiangady, B., \& Shetty, A. K. (2008). Aging does not alter the number or phenotype of putative stem/progenitor cells in the neurogenic region of the hippocampus. Neurobiol Aging, 29(1), 129-147. doi:10.1016/j.neurobiolaging.2006.09.015

Hattiangady, B., \& Shetty, A. K. (2010). Decreased neuronal differentiation of newly generated cells underlies reduced hippocampal neurogenesis in chronic temporal lobe epilepsy. Hippocampus, 20(1), 97-112. doi:10.1002/hipo.20594

Haydar, T. F., Wang, F., Schwartz, M. L., \& Rakic, P. (2000). Differential modulation of proliferation in the neocortical ventricular and subventricular zones. $J$ Neurosci, 20(15), 5764-5774.

Howell, O. W., Doyle, K., Goodman, J. H., Scharfman, H. E., Herzog, H., Pringle, A., . . . Gray, W. P. (2005). Neuropeptide $Y$ stimulates neuronal precursor proliferation in the post-natal and adult dentate gyrus. $J$ Neurochem, 93(3), 560-570. doi:10.1111/j.1471-4159.2005.03057.x 
Howell, O. W., Scharfman, H. E., Herzog, H., Sundstrom, L. E., Beck-Sickinger, A., \& Gray, W. P. (2003). Neuropeptide $Y$ is neuroproliferative for post-natal hippocampal precursor cells. $J$ Neurochem, 86(3), 646-659. doi:1895 [pii]

Howell, O. W., Silva, S., Scharfman, H. E., Sosunov, A. A., Zaben, M., Shtaya, A., . . . Gray, W. P. (2007). Neuropeptide $Y$ is important for basal and seizure-induced precursor cell proliferation in the hippocampus. Neurobiol Dis, 26(1), 174-188. doi:10.1016/j.nbd.2006.12.014

Huang, X., Kong, H., Tang, M., Lu, M., Ding, J. H., \& Hu, G. (2012). D-Serine regulates proliferation and neuronal differentiation of neural stem cells from postnatal mouse forebrain. CNS Neurosci Ther, 18(1), 4-13. doi:10.1111/j.1755-5949.2011.00276.x

Huttmann, K., Sadgrove, M., Wallraff, A., Hinterkeuser, S., Kirchhoff, F., Steinhauser, C., \& Gray, W. P. (2003). Seizures preferentially stimulate proliferation of radial glia-like astrocytes in the adult dentate gyrus: functional and immunocytochemical analysis. Eur J Neurosci, 18(10), 2769-2778.

Jessberger, S., Romer, B., Babu, H., \& Kempermann, G. (2005). Seizures induce proliferation and dispersion of doublecortin-positive hippocampal progenitor cells. Exp Neurol, 196(2), 342351. doi:10.1016/j.expneurol.2005.08.010

Jessberger, S., Zhao, C., Toni, N., Clemenson, G. D., Jr., Li, Y., \& Gage, F. H. (2007). Seizureassociated, aberrant neurogenesis in adult rats characterized with retrovirus-mediated cell labeling. J Neurosci, 27(35), 9400-9407. doi:10.1523/JNEUROSCI.2002-07.2007

Jiruska, P., Shtaya, A. B., Bodansky, D. M., Chang, W. C., Gray, W. P., \& Jefferys, J. G. (2013). Dentate gyrus progenitor cell proliferation after the onset of spontaneous seizures in the tetanus toxin model of temporal lobe epilepsy. Neurobiol Dis, 54, 492-498. doi:10.1016/j.nbd.2013.02.001

Kapus, G. L., Gacsalyi, I., Vegh, M., Kompagne, H., Hegedus, E., Leveleki, C., . . . Levay, G. (2008). Antagonism of AMPA receptors produces anxiolytic-like behavior in rodents: effects of GYKI 52466 and its novel analogues. Psychopharmacology (Berl), 198(2), 231-241. doi:10.1007/s00213-008-1121-z

Kita, Y., Ago, Y., Higashino, K., Asada, K., Takano, E., Takuma, K., \& Matsuda, T. (2014). Galantamine promotes adult hippocampal neurogenesis via $M(1)$ muscarinic and alpha7 nicotinic receptors in mice. Int J Neuropsychopharmacol, 17(12), 1957-1968. doi:10.1017/S1461145714000613

Kriegstein, A., \& Alvarez-Buylla, A. (2009). The glial nature of embryonic and adult neural stem cells. Annu Rev Neurosci, 32, 149-184. doi:10.1146/annurev.neuro.051508.135600

Kunze, A., Congreso, M. R., Hartmann, C., Wallraff-Beck, A., Huttmann, K., Bedner, P., . . . Steinhauser, C. (2009). Connexin expression by radial glia-like cells is required for neurogenesis in the adult dentate gyrus. Proc Natl Acad Sci U S A, 106(27), 11336-11341. doi:10.1073/pnas.0813160106

Liu, X., Wang, Q., Haydar, T. F., \& Bordey, A. (2005). Nonsynaptic GABA signaling in postnatal subventricular zone controls proliferation of GFAP-expressing progenitors. Nat Neurosci, 8(9), 1179-1187. doi:10.1038/nn1522

Lopez, T., Lopez-Colome, A. M., \& Ortega, A. (1994). AMPA/KA receptor expression in radial glia. Neuroreport, 5(4), 504-506.

Lugert, S., Basak, O., Knuckles, P., Haussler, U., Fabel, K., Gotz, M., . . . Giachino, C. (2010). Quiescent and active hippocampal neural stem cells with distinct morphologies respond selectively to physiological and pathological stimuli and aging. Cell Stem Cell, 6(5), 445456. doi:S1934-5909(10)00146-3 [pii]

10.1016/j.stem.2010.03.017

Martins, R. A., Linden, R., \& Dyer, M. A. (2006). Glutamate regulates retinal progenitors cells proliferation during development. Eur J Neurosci, 24(4), 969-980. doi:10.1111/j.14609568.2006.04966.x

Matthias, K., Kirchhoff, F., Seifert, G., Huttmann, K., Matyash, M., Kettenmann, H., \& Steinhauser, C. (2003). Segregated expression of AMPA-type glutamate receptors and glutamate transporters defines distinct astrocyte populations in the mouse hippocampus. $J$ Neurosci, 23(5), 1750-1758.

Morrens, J., Van Den Broeck, W., \& Kempermann, G. (2012). Glial cells in adult neurogenesis. Glia, 60(2), 159-174. doi:10.1002/glia.21247

Moss, J., Gebara, E., Bushong, E. A., Sanchez-Pascual, I., O'Laoi, R., El M'Ghari, I., . . . Toni, N. (2016). Fine processes of Nestin-GFP-positive radial glia-like stem cells in the adult dentate 
gyrus ensheathe local synapses and vasculature. Proc Natl Acad Sci U S A, 113(18), E25362545. doi:10.1073/pnas.1514652113

Nakagawa, E., Aimi, Y., Yasuhara, O., Tooyama, I., Shimada, M., McGeer, P. L., \& Kimura, H. (2000). Enhancement of progenitor cell division in the dentate gyrus triggered by initial limbic seizures in rat models of epilepsy. Epilepsia, 41(1), 10-18.

Noctor, S. C., Flint, A. C., Weissman, T. A., Dammerman, R. S., \& Kriegstein, A. R. (2001). Neurons derived from radial glial cells establish radial units in neocortex. Nature, 409(6821), 714720. doi: $10.1038 / 35055553$

Noctor, S. C., Martinez-Cerdeno, V., \& Kriegstein, A. R. (2008). Distinct behaviors of neural stem and progenitor cells underlie cortical neurogenesis. J Comp Neurol, 508(1), 28-44. doi:10.1002/cne.21669

Parent, J. M., Yu, T. W., Leibowitz, R. T., Geschwind, D. H., Sloviter, R. S., \& Lowenstein, D. H. (1997). Dentate granule cell neurogenesis is increased by seizures and contributes to aberrant network reorganization in the adult rat hippocampus. $J$ Neurosci, 17(10), 37273738.

Parenti, S., Casagrande, G., Montanari, M., Espahbodinia, M., Ettari, R., Grande, A., \& Corsi, L. (2016). A novel 2,3-benzodiazepine-4-one derivative AMPA antagonist inhibits G2/M transition and induces apoptosis in human leukemia Jurkat T cell line. Life Sci, 152, 117125. doi:10.1016/j.lfs.2016.03.051

Pollard, H., Heron, A., Moreau, J., Ben-Ari, Y., \& Khrestchatisky, M. (1993). Alterations of the GluR-B AMPA receptor subunit flip/flop expression in kainate-induced epilepsy and ischemia. Neuroscience, 57(3), 545-554. doi:0306-4522(93)90004-Y [pii]

Rakic, P., \& Sidman, R. L. (1973). Weaver mutant mouse cerebellum: defective neuronal migration secondary to abnormality of Bergmann glia. Proc Natl Acad Sci U S A, 70(1), 240-244.

Renzel, R., Sadek, A. R., Chang, C. H., Gray, W. P., Seifert, G., \& Steinhauser, C. (2013). Polarized distribution of AMPA, but not GABAA, receptors in radial glia-like cells of the adult dentate gyrus. Glia, 61(7), 1146-1154. doi:10.1002/glia.22505

Scharfman, H. E., Goodman, J. H., \& Sollas, A. L. (2000). Granule-like neurons at the hilar/CA3 border after status epilepticus and their synchrony with area CA3 pyramidal cells: functional implications of seizure-induced neurogenesis. J Neurosci, 20(16), 6144-6158.

Schitine, C., Xapelli, S., Agasse, F., Sarda-Arroyo, L., Silva, A. P., De Melo Reis, R. A., . . . Malva, J. O. (2012). Ampakine CX546 increases proliferation and neuronal differentiation in subventricular zone stem/progenitor cell cultures. Eur J Neurosci, 35(11), 1672-1683. doi:10.1111/j.1460-9568.2012.08072.x

Schmittgen, T. D. (2001). Real-time quantitative PCR. Methods, 25(4), 383-385. doi:10.1006/meth.2001.1260

S1046-2023(01)91260-5 [pii]

Seri, B., Garcia-Verdugo, J. M., Collado-Morente, L., McEwen, B. S., \& Alvarez-Buylla, A. (2004). Cell types, lineage, and architecture of the germinal zone in the adult dentate gyrus. $J$ Comp Neurol, 478(4), 359-378. doi:10.1002/cne.20288

Seri, B., Garcia-Verdugo, J. M., McEwen, B. S., \& Alvarez-Buylla, A. (2001). Astrocytes give rise to new neurons in the adult mammalian hippocampus. J Neurosci, 21(18), 7153-7160.

Shapiro, L. A., \& Ribak, C. E. (2006). Newly born dentate granule neurons after pilocarpine-induced epilepsy have hilar basal dendrites with immature synapses. Epilepsy Res, 69(1), 53-66. doi:10.1016/j.eplepsyres.2005.12.003

Shors, T. J. (2008). From stem cells to grandmother cells: how neurogenesis relates to learning and memory. Cell Stem Cell, 3(3), 253-258. doi:S1934-5909(08)00408-6 [pii]

10.1016/j.stem.2008.08.010

Shors, T. J., Miesegaes, G., Beylin, A., Zhao, M., Rydel, T., \& Gould, E. (2001). Neurogenesis in the adult is involved in the formation of trace memories. Nature, 410(6826), 372-376. doi: $10.1038 / 35066584$

35066584 [pii]

Sierra, A., Martin-Suarez, S., Valcarcel-Martin, R., Pascual-Brazo, J., Aelvoet, S. A., Abiega, O., . . . Encinas, J. M. (2015). Neuronal hyperactivity accelerates depletion of neural stem cells and impairs hippocampal neurogenesis. Cell Stem Cell, 16(5), 488-503. doi:10.1016/j.stem.2015.04.003

Song, J., Zhong, C., Bonaguidi, M. A., Sun, G. J., Hsu, D., Gu, Y., . . . Song, H. (2012). Neuronal circuitry mechanism regulating adult quiescent neural stem-cell fate decision. Nature, 489(7414), 150-154. doi:10.1038/nature11306 
Spalding, K. L., Bergmann, O., Alkass, K., Bernard, S., Salehpour, M., Huttner, H. B., . . . Frisen, J. (2013). Dynamics of hippocampal neurogenesis in adult humans. Cell, 153(6), 1219-1227. doi:10.1016/j.cell.2013.05.002

Steiner, B., Klempin, F., Wang, L., Kott, M., Kettenmann, H., \& Kempermann, G. (2006). Type-2 cells as link between glial and neuronal lineage in adult hippocampal neurogenesis. Glia, 54(8), 805-814. doi:10.1002/glia.20407

Steiner, B., Zurborg, S., Horster, H., Fabel, K., \& Kempermann, G. (2008). Differential 24 h responsiveness of Prox1-expressing precursor cells in adult hippocampal neurogenesis to physical activity, environmental enrichment, and kainic acid-induced seizures. Neuroscience, 154(2), 521-529. doi:10.1016/j.neuroscience.2008.04.023

Su, X. W., Li, X. Y., Banasr, M., Koo, J. W., Shahid, M., Henry, B., \& Duman, R. S. (2009a). Chronic treatment with AMPA receptor potentiator Org 26576 increases neuronal cell proliferation and survival in adult rodent hippocampus. Psychopharmacology (Berl). doi:10.1007/s00213009-1598-0

Su, X. W., Li, X. Y., Banasr, M., Koo, J. W., Shahid, M., Henry, B., \& Duman, R. S. (2009b). Chronic treatment with AMPA receptor potentiator Org 26576 increases neuronal cell proliferation and survival in adult rodent hippocampus. Psychopharmacology (Berl), 206(2), 215-222. doi:10.1007/s00213-009-1598-0

Sultan, S., Gebara, E. G., Moullec, K., \& Toni, N. (2013). D-serine increases adult hippocampal neurogenesis. Front Neurosci, 7, 155. doi:10.3389/fnins.2013.00155

Talos, D. M., Follett, P. L., Folkerth, R. D., Fishman, R. E., Trachtenberg, F. L., Volpe, J. J., \& Jensen, F. E. (2006). Developmental regulation of alpha-amino-3-hydroxy-5-methyl-4isoxazole-propionic acid receptor subunit expression in forebrain and relationship to regional susceptibility to hypoxic/ischemic injury. II. Human cerebral white matter and cortex. J Comp Neurol, 497(1), 61-77. doi:10.1002/cne.20978

Tozuka, Y., Fukuda, S., Namba, T., Seki, T., \& Hisatsune, T. (2005). GABAergic excitation promotes neuronal differentiation in adult hippocampal progenitor cells. Neuron, 47(6), 803-815. doi:10.1016/j.neuron.2005.08.023

Wang, L. P., Kempermann, G., \& Kettenmann, H. (2005). A subpopulation of precursor cells in the mouse dentate gyrus receives synaptic GABAergic input. Mol Cell Neurosci, 29(2), 181-189. doi:10.1016/j.mcn.2005.02.002

Whitney, N. P., Peng, H., Erdmann, N. B., Tian, C., Monaghan, D. T., \& Zheng, J. C. (2008). Calcium-permeable AMPA receptors containing Q/R-unedited GluR2 direct human neural progenitor cell differentiation to neurons. FASEB J, 22(8), 2888-2900. doi:fj.07-104661 [pii] 10.1096/fj.07-104661

Xing, L., Esau, C., \& Trudeau, V. L. (2015). Direct Regulation of Aromatase B Expression by 17betaEstradiol and Dopamine D1 Receptor Agonist in Adult Radial Glial Cells. Front Neurosci, 9, 504. doi:10.3389/fnins.2015.00504

Zaben, M., Sheward, W. J., Shtaya, A., Abbosh, C., Harmar, A. J., Pringle, A. K., \& Gray, W. P. (2009). The neurotransmitter VIP expands the pool of symmetrically dividing postnatal dentate gyrus precursors via VPAC2 receptors or directs them toward a neuronal fate via VPAC1 receptors. Stem Cells, 27(10), 2539-2551. doi:10.1002/stem.184

Figure Legends

FIGURE 1:

Kainate is a positive survival factor for hippocampal cells after 5 days in-vitro through

AMPARs and not kainate receptors. 
Quantification of live cells (DAPI+, Mitotracker+ PI-/DAPI, A) and dying cells (DAPI+ Mitotracker+PI+/DAPI, B) among the total number of cells, after 5 days of treatment with 5 $\mu \mathrm{M}$ of kainate. Data represents $\mathrm{n}=3$ independent experiments. Means were compared using unpaired Student's t-test. $* * \mathrm{p}<0.01 ; * * * \mathrm{p}<0.001$.

Quantification of apoptotic cells (caspase3+) in the neuronal precursor (Tuj1+; C) or progenitor (nestin+; E) cell populations, after 5 days of treatment with $5 \mu \mathrm{M}$ of kainate. Images show confocal co-localization of activated caspase3 (red; D \& F) and Tuj1 (green; D) or nestin (green; F) after 5 days of treatment with $5 \mu \mathrm{M}$ of kainate. This has been confirmed by Western-blot $(\mathbf{G})$, showing a decrease in the fragments of activated caspase-3 (17 and $19 \mathrm{kDa}$ bands) whereas activated caspase-3 (35kDa band) does not change. Data represents $\mathrm{n}=3$ independent experiments. Means were compared using unpaired Student's t-test. $* * \mathrm{p}<0.01 ; * * * \mathrm{p}<0.001$. Scale bar $=20 \mu \mathrm{m}$

(H) Using time-lapse imaging between days 3 and 5, from at least 2 separate experiments, kainate increases survival of hippocampal cells. Degrees of freedom: 1 , Chi-square $=30.97$ and $\mathrm{p}<0.0001$

(I) Kainate $(5 \mu \mathrm{M})$ increases the total number of cells labeled with DAPI after 5 days in culture, and this effect is abolished by blocking AMPARs. Hippocampal cultured cells were maintained under control conditions alone or in the addition of either $30 \mu \mathrm{M}$ NBQX, $10 \mu \mathrm{M}$ GYKI52466, $5 \mu \mathrm{M}$ kainate, $5 \mu \mathrm{M}$ kainate and $30 \mu \mathrm{M}$ NBQX, or $5 \mu \mathrm{M}$ kainate and $10 \mu \mathrm{M}$ GYKI52466. Our results demonstrate a significant rise in the total numbers of cells (DAPI+) after 5 days of kainate exposure, which was abolished by the addition of either NBQX or GYKI52466 to kainate-treated cells. Data represents $n \geq 3$ independent experiments, 4-8 wells per condition per experiment. Means were compared using one way ANOVA with Dunnett's multiple comparison test. $* * * \mathrm{p}<0.001$. 


\section{FIGURE 2:}

Kainate is a proliferative factor for nestin + cells and TuJ1+ cells after 3 days in-vitro.

(A) Quantification of proliferating cells in S phase (BrdU+) among the total number of cells, after 3 days of treatment with $5 \mu \mathrm{M}$ of kainate (black bars) versus control (grey bars). Data represents $n \geq 2$ independent experiments, 4-8 wells per condition per experiment. Statistical differences were analyzed using two way ANOVA with Bonferroni's multiple comparison test. $* * \mathrm{p}<0.01, * * * \mathrm{p}<0.001$ when comparing kainate conditions across time; $++\mathrm{p}<0.01$, $+++\mathrm{p}<0.001$ when comparing control conditions across time; $\mathrm{xx} p<0.01$ when comparing control to kainate at each time point.

Quantification of the mitotic indexes: proliferating cells in S phase $(\mathrm{BrdU}+)$ in the precursor (nestin+; B,C) and neuronal progenitor (Tuj1+; D,E) cell populations, after 3 days of treatment with $5 \mu \mathrm{M}$ kainate $(\mathrm{B}, \mathrm{D})$ or a short pulse of kainate of $6 \mathrm{~h}$ on day $3(\mathrm{C}, \mathrm{E})$. Data represents $n=3$ independent experiments. Means were compared using unpaired Student's ttest. $* * \mathrm{p}<0.01 ; * * * \mathrm{p}<0.001$

(F) Confocal images show co-localization of BrdU (green), nestin (purple) and Ki67 (red). White arrow shows a triple labeled cell whereas yellow arrow shows a proliferating $(\mathrm{Ki} 67+)$ nestin + cell not in S phase at the time of staining (BrdU-) Scale bar $=57 \mu \mathrm{m}$.

(G) Quantification of the growth fraction: proliferating cells (Ki67+) in the total population (DAPI + ) after a short pulse of kainate of $6 \mathrm{~h}$ on day 3 . Data represents $\mathrm{n}=3$ independent experiments. Means were compared using unpaired Student's t-test.

(H) Quantification of the labeling index: This table shows the number of proliferating cells in S phase (BrdU+) among the proliferating nestin+ population (Ki67+nestin+) after cells were grown for 3 days before being pulsed with $5 \mu \mathrm{M}$ kainate and $\mathrm{BrdU}$ for the last $6 \mathrm{~h}$. We quantified 100 nestin+ cells for the expression of BrdU and Ki67 before and after kainate 
treatment. Our results reveals that kainate treatment enhances the proliferation rate of nestin progenitor cells. Degrees of freedom: 1 , Chi-square $=12.3$ and $p<0.001$.

\section{FIGURE3:}

Kainate is a positive proliferative factor for type-1 (nestin+ GFAP+) cells but not for type-2 (nestin+ GFAP-) cells after 3 days in-vitro.

Using time lapse imaging of cellular divisions, kainate shows no general proliferative effect on the populations of either nestin $+\mathrm{TuJ} 1$ - cells or neuronal progenitors (nestin $+\mathrm{TuJ} 1+$ ) cells (A), whereas it shows a specific effect on type-1 (nestin+ GFAP+) cells versus type-2 (nestin+ GFAP-) cells $(\mathrm{B}$; Chi square $=6.6$ and $\mathrm{p}=0.01 ; \mathrm{Z}$ value $2.6, \mathrm{p}<0.05$ for nestin+ GFAP + cells). Cell divisions in control and kainate conditions were analyzed and the daughter cells were analyzed for nestin, TuJ1 and GFAP expression.

(C) Using BrdU to label dividing cells, kainate shows a specific proliferative effect on type-1 $($ nestin + GFAP + ) cells versus type-2 (nestin + GFAP-) cells (Chi square $=36.8$ and $p<0.0001$; $Z$ value $4.5 \mathrm{p}<0.05$ for nestin + GFAP+ cells; $Z$ value $5.1 \mathrm{p}<0.05$ for nestin + GFAP- cells) .

(D) Confocal images show co-localization of BrdU (green), nestin (red) and GFAP (blue). Scale bar $=25 \mu \mathrm{m}$

(E) Time lapse video pictures of hippocampal cells dividing for $48 \mathrm{~h}$ between day 2 and 4 after kainate treatment. The cell marked by red arrow divides after $6 \mathrm{~h}$ to give two cells marked by yellow and red arrows. The cell indicated by the red arrow divides again after $38 \mathrm{~h}$ to give rise to a blue arrowed cell and a red arrowed cell. In this example, the cell cycle lasted $32 \mathrm{~h}$.

(F) Immunocytochemistry of the same cells as in E after time-lapse video microscopy. Colocalization of nestin (green) and GFAP (red) with DAPI (blue), with orthogonal views on the right and bottom of each picture. The red arrow cell has been washed away during the immunocytochemistry procedure. Scale bar $=100 \mu \mathrm{m}$. 
(G) Images of radial glia-like cells showing confocal co-localization of GFAP (green), BLBP (red) and DAPI (blue). Scale bar $=50 \mu \mathrm{m}$. 
FIGURE 4:

Kainate stimulates proliferative through AMPARs and not kainate receptors.

Quantification of the nestin+ cells (A), TuJ1+cells (B), BrdU+ cells (mitotic index, C) and percentage of cells in $\mathrm{S}$ phase in the proliferating population $(\mathrm{Ki} 67+\mathrm{BrdU}+/ \mathrm{Ki} 67+$; labeling index; D) after a short pulse of $5 \mu \mathrm{M}$ of kainate and/or inhibitors for $6 \mathrm{~h}$ on day 3 . Hippocampal cultured cells were maintained under either control conditions alone or received a short pulse $(6 \mathrm{~h}$ ) of either $30 \mu \mathrm{M}$ NBQX (potent and selective inhibitor of both AMPARs and kainate receptors), $10 \mu \mathrm{M}$ GYKI52466 (mainly AMPAR antagonist), $5 \mu \mathrm{M}$ kainate, 5 $\mu \mathrm{M}$ kainate and $30 \mu \mathrm{M}$ NBQX, or $5 \mu \mathrm{M}$ kainate and $10 \mu \mathrm{M}$ GYKI52466. Data represents $\mathrm{n} \geq 2$ independent experiments, with $4-8$ wells per condition per experiment. Statistical differences were analyzed with one way ANOVA with Dunnett's multiple comparison test, $* * * \mathrm{p}<0.001$

(E) AMPA increases cell proliferation rate. Percentage of cells in S phase in the proliferating population (Ki67+BrdU+/Ki67+; labeling index) after an $8 \mathrm{~h}$ pulse of $1 \mu \mathrm{M}$ AMPA on day 3 . Means were compared using unpaired Student's t-test. ${ }^{* * *} \mathrm{p}<0.001$.

(F) Hippocampal cell cultures express glutamate receptors transcripts. RT-PCR gels demonstrate the presence of AMPA receptors units: GluA1, GluA2, GluA3, and GluA4 mRNAs in hippocampal NSPC cultures (lane2), as well as in whole brain tissue extracts (lane 1) but not in negative control (lane 3 ).

(G) Immunocytochemistry expression of GluA2 on progenitor cells. Image shows confocal co-localization of GluA2 (green), nestin (blue), GFAP (red) and DAPI (white) in hippocampal precursor cell culture. Scale bar $=35 \mu \mathrm{m}$.

FIGURE 5: 
Characterization of AMPA and $\mathrm{GABA}_{\mathrm{A}}$ receptor expression in RG-like cells in-vitro.

A) Whole cell membrane currents of a neuronal progenitor cell elicited by applying de- and hyperpolarization voltage steps. (B) After blocking $\mathrm{K}^{+}$and $\mathrm{Na}^{+}$currents, AMPAR currents were evoked by bath application of the AMPA/kainate receptor agonist kainate $(500 \mu \mathrm{M})$ and the AMPA receptor modulator CTZ $(100 \mu \mathrm{M})$ for $30 \mathrm{~s}$. and receptor currents were blocked by the subsequent application of the AMPA/kainate receptor blocker NBQX $(20 \mu \mathrm{M})$. The corresponding I/V relation is shown in the right panel. (C) $\mathrm{GABA}_{\mathrm{A}}$ receptor responses were activated on a whole cell recording cell by application of muscimol $(100 \mu \mathrm{M})$ together with the receptor modulator PBT $(50 \mu \mathrm{M})$. The $\mathrm{I} / \mathrm{V}$ relation of the $\mathrm{GABA}_{\mathrm{A}}$ receptor response is shown in the right panel. (D) Single cell RT-PCR showed co-expression of the RG-like cell marker BLPB and GFAP as well as GluA2 in the same cells. After harvesting of the cytoplasm of the electrophysiologically characterized cell, a single cell RT-PCR was performed. The agarose gel shows the co-expression of GFAP and the radial glia cell marker BLPB and the GluA2 subunit of AMPA receptors. The DNA bands were detected at the expected position. A low molecular weight DNA ladder (NEB, Frankfurt, Germany) was used as molecular weight marker.

\section{FIGURE 6:}

Kainate stimulates proliferation of RG-like cells in the dentate gyrus in-vivo.

(A) Quantification of the proliferating cells $(\mathrm{Ki} 67+)$ in the dentate gyri. Data represents $\mathrm{n}=6$ animals per group. Statistical differences were analyzed with two-way ANOVA with Bonferroni’s multiple comparison test. $* * \mathrm{p}<0.01, * * * \mathrm{p}<0.001$.

(B) Quantification of the RG-like cells' proliferation in the dentate gyrus at $72 \mathrm{H}$. Quantification of Ki67+ and Radial Glia-like GFAP+ cells, counting $30 \mathrm{Ki} 67+$ cells per SGZ, from a stereological sample of 5 sections per animal, in 5 animals (total 150 cells) and similarly 152 RG-like GFAP+ cells. Ki67+ cells: Chi square=9.3, $\mathrm{p}<0.01 ; \mathrm{Z}=2.8, \mathrm{p}<0.05$ for 
Ki67+GFAP + cells; Z=2.9, p $<0.05$ for Ki67+GFAP- cells; GFAP+ cells: Chi square=9.2, $\mathrm{p}<0.01 ; \mathrm{Z}=52.9, \mathrm{p}<0.001$ for GFAP+Ki67+ cells; $\mathrm{Z}=5.82 .9, \mathrm{p}<0.001$ for GFAP+Ki67- cells. (C), (D) Seizures recruit a pre-labelled clone of RG-like cells to proliferate. Quantification of the number of proliferating (Ki67+) GFAP+ RG-like cells at $72 \mathrm{~h}(17,071 \pm 909$ after SE vs $\underline{6,042 \pm 418 \text { in control animals, Two-way ANOVA with Benferroni post-hoc test, } \mathrm{p}<0.001) \text { in }}$ the SGZ and GCL of the DG. The non-RG-like population increased significantly in SE when compared to control (22731 cells vs 29067 cells, Two-way ANOVA with Bonferroni's posthoc test, $\mathrm{p}=0.04$ ) (D) the proportion of proliferating RG-like pre-labelled cells (GFAP+ $\mathrm{BrdU}+\mathrm{Ki} 67+)$ that arose from the constitutively proliferating population $(\mathrm{GFAP}+\mathrm{Ki} 67+)$ (185 cells, $2.9 \% \pm 0.3 \%$ under control vs 809 cells, $4.4 \% \pm 0.3 \%$ under SE, $p=0.04)$. Data represents $n=6$ animals per group. Means were compared using Two-way ANOVA with $\underline{\text { Benferroni post-hoc test in panel and unpaired Student's t-test in panel D and, }}{ }^{*} \mathrm{p}<0.05$.

(E) Seizures preferentially recruit the pre-labelled clone of proliferating cells. Data shows that BrdU labelled RG-like cells (pre-labelled clone) are double the unlabelled RG-like cells under seizures condition. This confirms a significant recruitment of the pre-labelled clone of RG-like cells. Data represents $n=6$ animals per group. Means were compared using unpaired Student's t-test, ${ }^{*} \mathrm{p}<0.05$

(F) Seizures enhance cell proliferation in the dentate gyri. Quantification of the formerly proliferating clone of precursor cells $(\mathrm{BrdU}+)$ in the dentate gyri. Data represents 12 dentate gyri from $n=6$ animals per group. Statistical differences were analyzed with two ways ANOVA with Bonferroni’s multiple comparison test. ${ }^{*} \mathrm{p}<0.01$.

(G) The effect of seizures on proliferating RG-like (GFAP+ Sox2+ Ki67+) cells in-vivo. Quantification of the proliferating type-1 (radial GFAP+,Sox2+,Ki67+) at $72 \mathrm{~h}$ after kainateinduced SE. Our results demonstrate a significant increase in the proliferating RG-like cells 
in the dentate gyri after seizures. Data represents $n=6$ animals per group. Means were compared using unpaired Student's t-test, $* * * \mathrm{p}<0.001$.

(H) Immunohistochemistry of control dentate gyrus. Confocal low magnification of maximum projection image that shows part of the DG and the three cell types immunstained. $\underline{\text { BrdU (green), Ki67 (blue) and GFAP (red). SGL; Subgranular zone, GCL; granular cell }}$ layer. Scale bar $=100.59 \mu \mathrm{m}$.

(J) Immunohistochemistry of SE dentate gyrus (72 h after SE induction). Confocal low magnification of maximum projection image that shows part of the DG and the three cell types immunstained. BrdU (green), Ki67 (blue) and GFAP (red). SGL; Subgranular zone, $\underline{\text { GCL; granular cell layer. Scale bar }=50.36 \mu \mathrm{m}}$

(I) Immunohistochemistry of an in-vivo RG-like cell. Confocal image shows co-localization of BrdU (green), Ki67 (blue) and GFAP (red), $72 \mathrm{~h}$ after kainate treatment. Scale bar $=$ $\underline{16.78 \mu \mathrm{m}}$ 

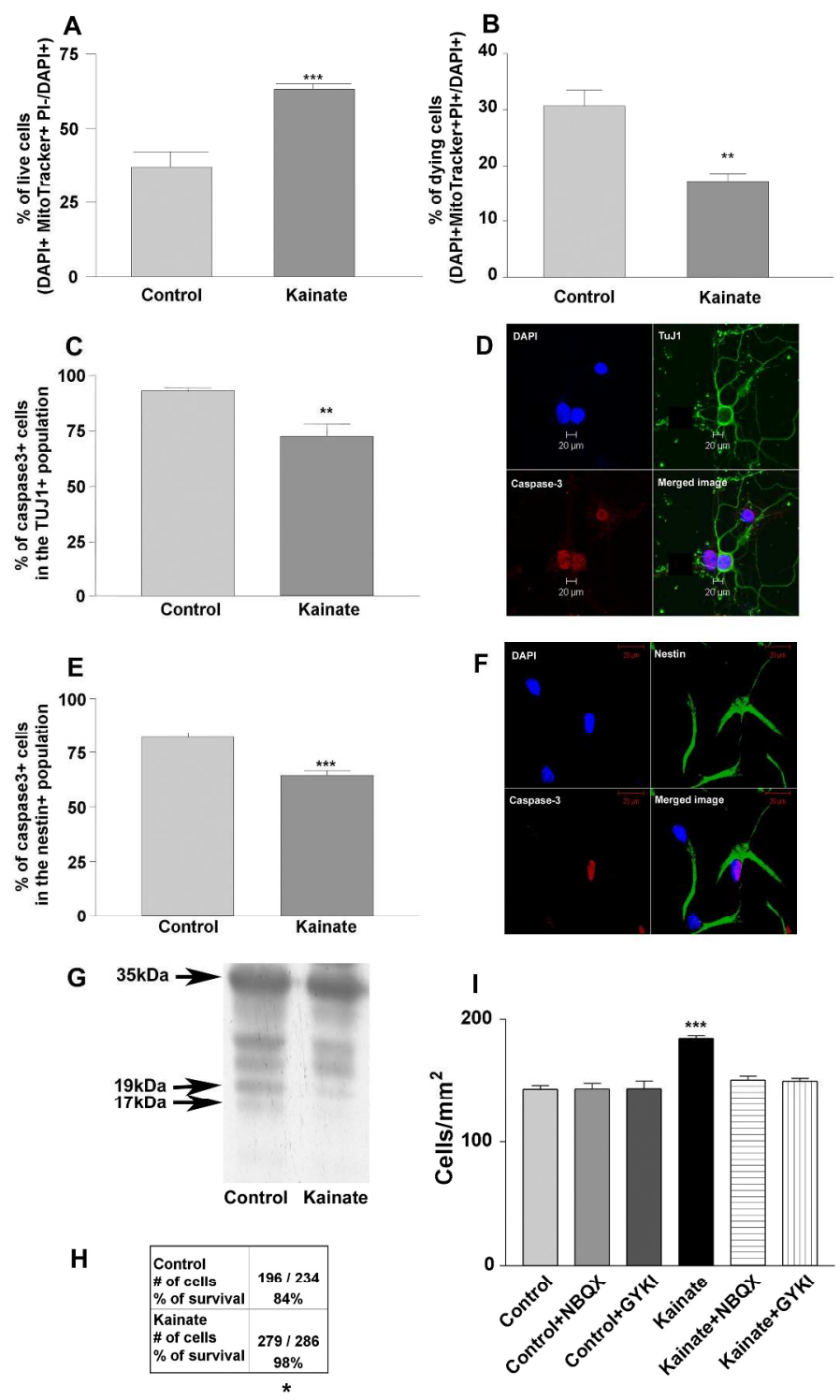

Kainate is a positive survival factor for hippocampal cells after 5 days in-vitro through AMPARs and not kainate receptors.

Quantification of live cells (DAPI+, Mitotracker+ PI-/DAPI, A) and dying cells (DAPI+ Mitotracker+PI+/DAPI, B) among the total number of cells, after 5 days of treatment with $5 \mu \mathrm{M}$ of kainate. Data represents $\mathrm{n}=3$ independent experiments. Means were compared using unpaired Student's t-test. $* * p<0.01 ; * * * p<0.001$. Quantification of apoptotic cells (caspase3+) in the neuronal precursor (Tuj1+; C) or progenitor (nestin+; E) cell populations, after 5 days of treatment with $5 \mu \mathrm{M}$ of kainate. Images show confocal co-localization of activated caspase3 (red; D \& F) and Tuj1 (green; D) or nestin (green; F) after 5 days of treatment with 5 $\mu \mathrm{M}$ of kainate. This has been confirmed by Western-blot (G), showing a decrease in the fragments of activated caspase-3 (17 and 19kDa bands) whereas activated caspase-3 (35kDa band) does not change. Data represents $\mathrm{n}=3$ independent experiments. Means were compared using unpaired Student's t-test. $* * \mathrm{p}<0.01 ; * * * \mathrm{p}<0.001$. Scale bar $=20 \mu \mathrm{m}$

(H) Using time-lapse imaging between days 3 and 5, from at least 2 separate experiments, kainate 
increases survival of hippocampal cells. Degrees of freedom: 1 , Chi-square $=30.97$ and $p<0.0001$

(I) Kainate $(5 \mu \mathrm{M})$ increases the total number of cells labeled with DAPI after 5 days in culture, and this effect is abolished by blocking AMPARs. Hippocampal cultured cells were maintained under control conditions alone or in the addition of either $30 \mu \mathrm{M}$ NBQX, $10 \mu \mathrm{M}$ GYKI52466, $5 \mu \mathrm{M}$ kainate, $5 \mu \mathrm{M}$ kainate and $30 \mu \mathrm{M}$ NBQX, or $5 \mu \mathrm{M}$ kainate and $10 \mu \mathrm{M}$ GYKI52466. Our results demonstrate a significant rise in the total numbers of cells (DAPI+) after 5 days of kainate exposure, which was abolished by the addition of either NBQX or GYKI52466 to kainate-treated cells. Data represents $n \geq 3$ independent experiments, 4-8 wells per condition per experiment. Means were compared using one way ANOVA with Dunnett's multiple comparison test. $* * * p<0.001$

$1058 \times 1824 \mathrm{~mm}(96 \times 96 \mathrm{DPI})$ 

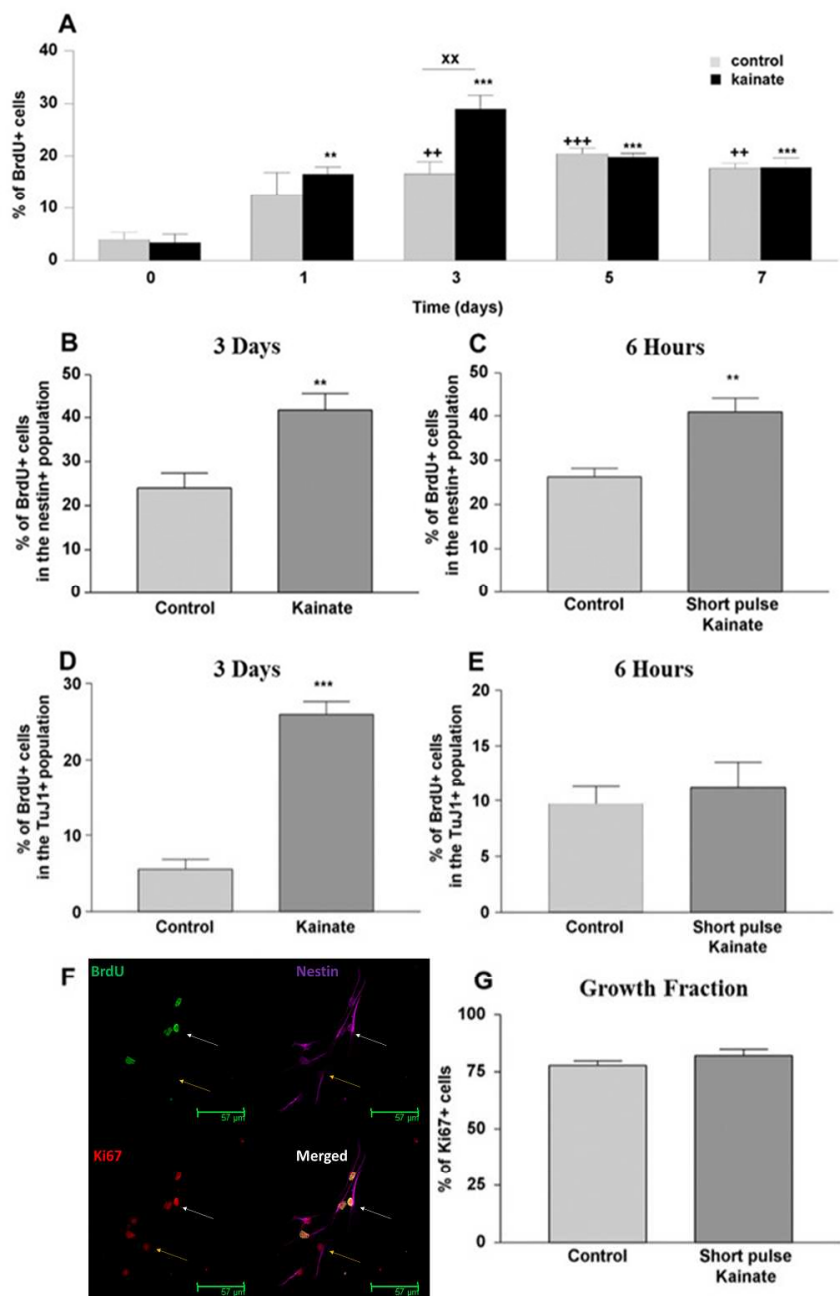

$\mathrm{H}$ The counts of the labelling index of progenitor cells (Nestin+/Ki67+/BrdU+) after kainate treatment

Nestin+Ki67+BrdU- Nestin+Ki67+BrdU+ Total

Control 80

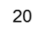

Kainate 57

P value * $<.05$

$*<.05$

Kainate is a proliferative factor for nestin + cells and TuJ1+ cells after 3 days in-vitro.

(A) Quantification of proliferating cells in S phase (BrdU+) among the total number of cells, after 3 days of treatment with $5 \mu \mathrm{M}$ of kainate (black bars) versus control (grey bars). Data represents $n \geq 2$ independent experiments, 4-8 wells per condition per experiment. Statistical differences were analyzed using two way

ANOVA with Bonferroni's multiple comparison test. $* * p<0.01, * * * p<0.001$ when comparing kainate conditions across time; $++p<0.01,+++p<0.001$ when comparing control conditions across time; $x x p<0.01$ when comparing control to kainate at each time point.

Quantification of the mitotic indexes: proliferating cells in $S$ phase (BrdU+) in the precursor (nestin+; B,C) and neuronal progenitor (Tuj1+; D,E) cell populations, after 3 days of treatment with $5 \mu M$ kainate $(B, D)$ or a short pulse of kainate of $6 \mathrm{~h}$ on day $3(C, E)$. Data represents $n=3$ independent experiments. Means were compared using unpaired Student's t-test. **p<0.01; ***p<0.001

(F) Confocal images show co-localization of BrdU (green), nestin (purple) and Ki67 (red). White arrow shows a triple labeled cell whereas yellow arrow shows a proliferating (Ki67+) nestin+ cell not in $\mathrm{S}$ phase at the 
time of staining (BrdU-). Scale bar $=57 \mu \mathrm{m}$.

(G) Quantification of the growth fraction: proliferating cells (Ki67+) in the total population (DAPI+) after a short pulse of kainate of $6 \mathrm{~h}$ on day 3. Data represents $n=3$ independent experiments. Means were compared using unpaired Student's t-test.

(H) Quantification of the labeling index: This table shows the number of proliferating cells in $\mathrm{S}$ phase (BrdU+) among the proliferating nestin+ population (Ki67+nestin+) after cells were grown for 3 days before being pulsed with $5 \mu \mathrm{M}$ kainate and BrdU for the last $6 \mathrm{~h}$. We quantified 100 nestin + cells for the expression of BrdU and Ki67 before and after kainate treatment. Our results reveals that kainate treatment enhances the proliferation rate of nestin progenitor cells. Degrees of freedom: 1 , Chi-square $=12.3$ and $p<0.001$. 
A

\begin{tabular}{|c|c|c|c|c|}
\hline & Total & $\begin{array}{c}\text { Nestin+ } \\
\text { TuJ1- }\end{array}$ & $\begin{array}{c}\text { Nestin+ } \\
\text { TuJ1+ }\end{array}$ & $\begin{array}{l}\text { Nestin- } \\
\text { TuJ1- }\end{array}$ \\
\hline $\begin{array}{l}\text { Control } \\
\# \text { of cells } \\
\% \text { of cells }\end{array}$ & $\begin{array}{c}36 \\
100 \%\end{array}$ & $\begin{array}{c}25 \\
70 \%\end{array}$ & $\begin{array}{c}3 \\
8 \%\end{array}$ & $\begin{array}{c}7 \\
19 \%\end{array}$ \\
\hline $\begin{array}{l}\text { Kainate } \\
\text { \# of cells } \\
\% \text { of cells }\end{array}$ & $\begin{array}{c}70 \\
100 \%\end{array}$ & $\begin{array}{c}52 \\
74 \%\end{array}$ & $\begin{array}{c}10 \\
14 \%\end{array}$ & $\begin{array}{c}8 \\
12 \%\end{array}$ \\
\hline
\end{tabular}

\section{C}

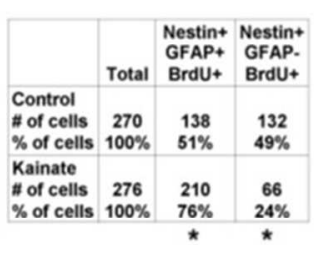

B

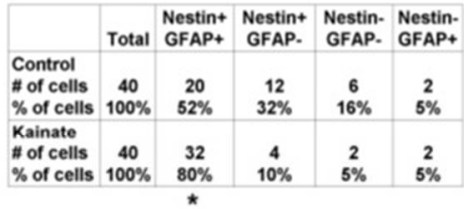

D

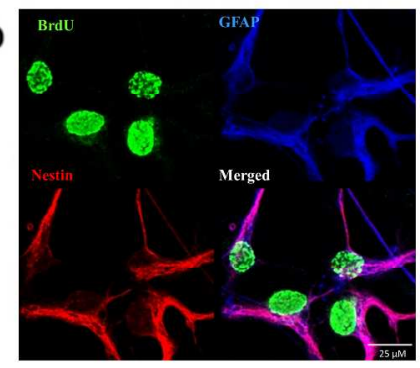

E
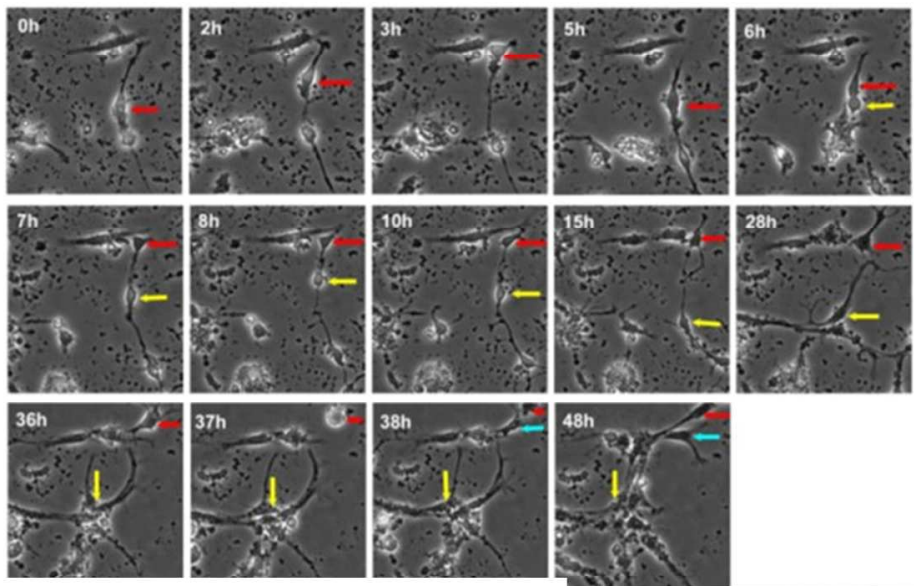

F
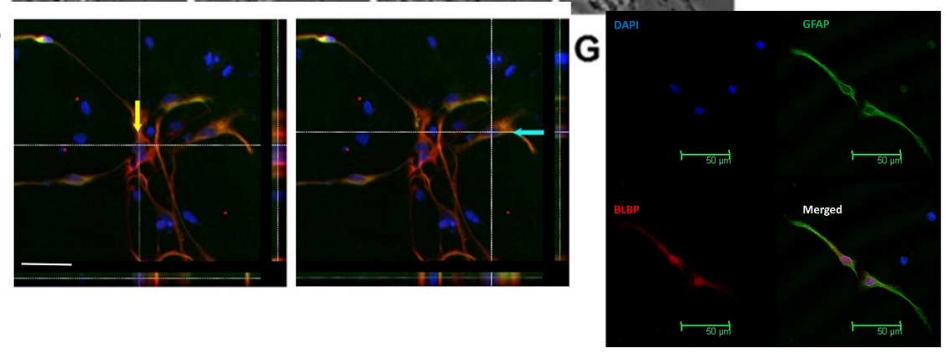

Kainate is a positive proliferative factor for type-1 (nestin + GFAP+) cells but not for type-2 (nestin+ GFAP-) cells after 3 days in-vitro.

Using time lapse imaging of cellular divisions, kainate shows no general proliferative effect on the populations of either nestin + TuJ1- cells or neuronal progenitors (nestin + TuJ1+) cells $(A)$, whereas it shows a specific effect on type-1 (nestin + GFAP+) cells versus type-2 (nestin+ GFAP-) cells ( $B$; Chi square $=$ 6.6 and $p=0.01 ; Z$ value $2.6, p<0.05$ for nestin + GFAP+ cells). Cell divisions in control and kainate conditions were analyzed and the daughter cells were analyzed for nestin, TuJ1 and GFAP expression.

(C) Using BrdU to label dividing cells, kainate shows a specific proliferative effect on type-1 (nestin+ GFAP+) cells versus type- 2 (nestin + GFAP-) cells (Chi square $=36.8$ and $p<0.0001 ; Z$ value $4.5 p<0.05$ for nestin+ GFAP+ cells; $Z$ value $5.1 \mathrm{p}<0.05$ for nestin+ GFAP- cells).

(D) Confocal images show co-localization of BrdU (green), nestin (red) and GFAP (blue). Scale bar $=25 \mu \mathrm{m}$.

(E) Time lapse video pictures of hippocampal cells dividing for $48 \mathrm{~h}$ between day 2 and 4 after kainate treatment. The cell marked by red arrow divides after $6 \mathrm{~h}$ to give two cells marked by yellow and red 
arrows. The cell indicated by the red arrow divides again after $38 \mathrm{~h}$ to give rise to a blue arrowed cell and a red arrowed cell. In this example, the cell cycle lasted $32 \mathrm{~h}$.

(F) Immunocytochemistry of the same cells as in E after time-lapse video microscopy. Co-localization of nestin (green) and GFAP (red) with DAPI (blue), with orthogonal views on the right and bottom of each picture. The red arrow cell has been washed away during the immunocytochemistry procedure. Scale bar $=$ $100 \mu \mathrm{m}$.

(G) Images of radial glia-like cells showing confocal co-localization of GFAP (green), BLBP (red) and DAPI (blue). Scale bar $=50 \mu \mathrm{m}$.

$661 \times 1053 \mathrm{~mm}(96 \times 96 \mathrm{DPI})$ 

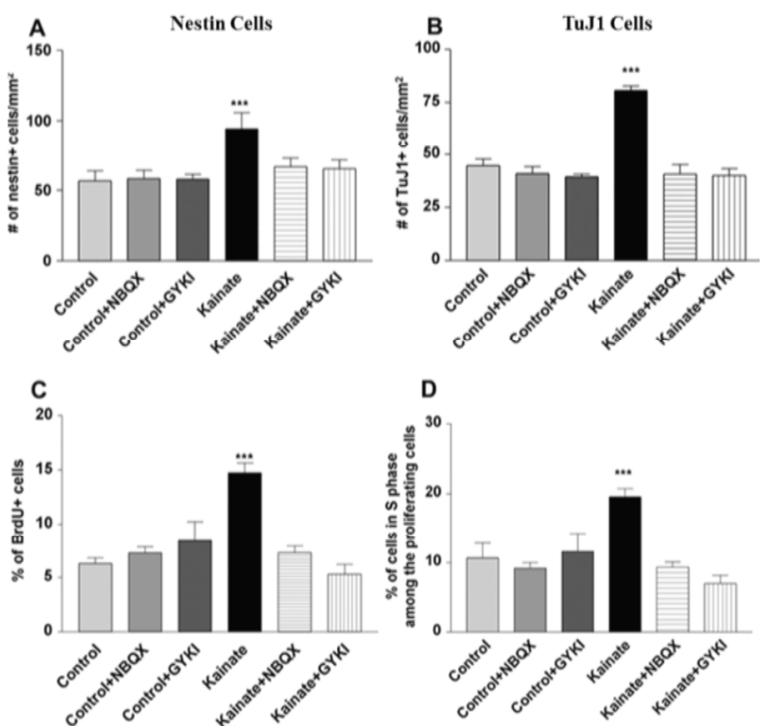

D
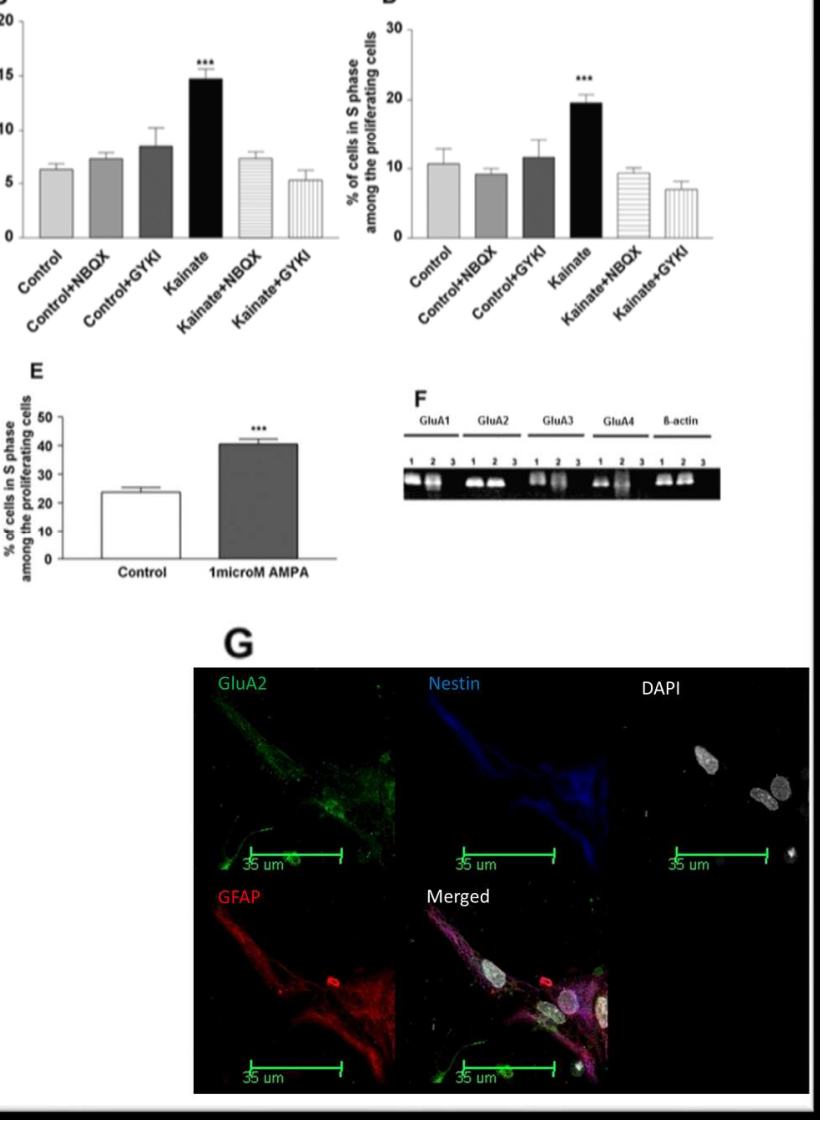

Kainate stimulates proliferative through AMPARs and not kainate receptors.

Quantification of the nestin + cells (A), TuJ1+cells (B), BrdU+ cells (mitotic index, C) and percentage of cells in $\mathrm{S}$ phase in the proliferating population (Ki67+BrdU+/Ki67+; labeling index; D) after a short pulse of $5 \mu \mathrm{M}$ of kainate and/or inhibitors for $6 \mathrm{~h}$ on day 3. Hippocampal cultured cells were maintained under either control conditions alone or received a short pulse $(6 \mathrm{~h}$ ) of either $30 \mu \mathrm{M}$ NBQX (potent and selective inhibitor of both AMPARs and kainate receptors), $10 \mu \mathrm{M}$ GYKI52466 (mainly AMPAR antagonist), $5 \mu \mathrm{M}$ kainate, $5 \mu \mathrm{M}$

kainate and $30 \mu \mathrm{M}$ NBQX, or $5 \mu \mathrm{M}$ kainate and $10 \mu \mathrm{M}$ GYKI52466. Data represents $\mathrm{n} \geq 2$ independent experiments, with 4-8 wells per condition per experiment. Statistical differences were analyzed with one way ANOVA with Dunnett's multiple comparison test, $* * * p<0.001$.

(E) AMPA increases cell proliferation rate. Percentage of cells in $S$ phase in the proliferating population (Ki67+BrdU+/Ki67+; labeling index) after an $8 \mathrm{~h}$ pulse of $1 \mu \mathrm{M}$ AMPA on day 3. Means were compared using unpaired Student's t-test. $* * * p<0.001$.

(F) Hippocampal cell cultures express glutamate receptors transcripts. RT-PCR gels demonstrate the 
presence of AMPA receptors units: GluA1, GluA2, GluA3, and GluA4 mRNAs in hippocampal NSPC cultures (lane2), as well as in whole brain tissue extracts (lane 1) but not in negative control (lane 3 ).

(G) Immunocytochemistry expression of GluA2 on progenitor cells. Image shows confocal co-localization of GluA2 (green), nestin (blue), GFAP (red) and DAPI (white) in hippocampal precursor cell culture. Scale bar $=35 \mu \mathrm{m}$.

$529 \times 931 \mathrm{~mm}(96 \times 96 \mathrm{DPI})$ 
A

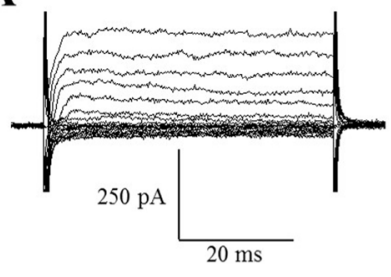

B

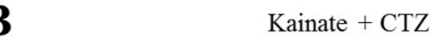

\section{Kainate $+\mathrm{CTZ}+\mathrm{NBQX}$}

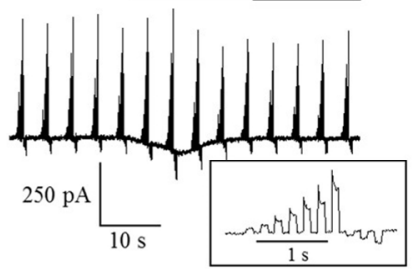

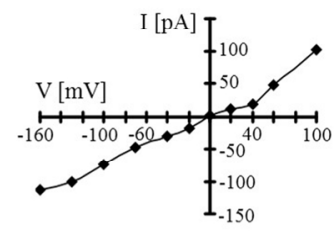

C $\quad$ Muscimol + PBT

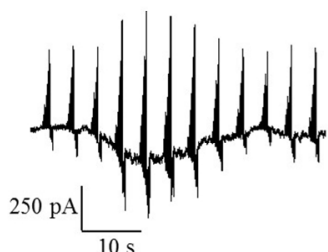

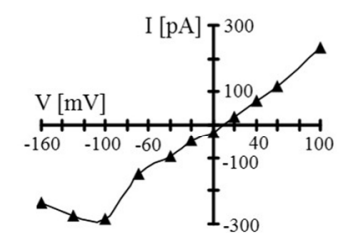

D

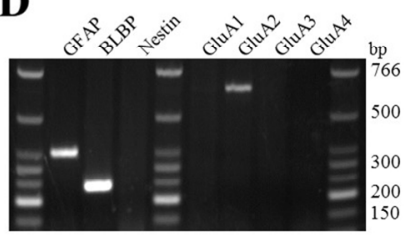

Characterization of AMPA and GABAA receptor expression in RG-like cells in-vitro.

A) Whole cell membrane currents of a neuronal progenitor cell elicited by applying de- and hyperpolarization voltage steps. (B) After blocking $\mathrm{K}+$ and $\mathrm{Na}+$ currents, AMPAR currents were evoked by bath application of the AMPA/kainate receptor agonist kainate $(500 \mu \mathrm{M})$ and the AMPA receptor modulator CTZ $(100 \mu \mathrm{M})$ for 30 $\mathrm{s}$. and receptor currents were blocked by the subsequent application of the AMPA/kainate receptor blocker NBQX $(20 \mu \mathrm{M})$. The corresponding I/V relation is shown in the right panel. (C) GABAA receptor responses were activated on a whole cell recording cell by application of muscimol $(100 \mu \mathrm{M})$ together with the receptor modulator PBT $(50 \mu \mathrm{M})$. The I/V relation of the GABAA receptor response is shown in the right panel. (D) Single cell RT-PCR showed co-expression of the RG-like cell marker BLPB and GFAP as well as GluA2 in the same cells. After harvesting of the cytoplasm of the electrophysiologically characterized cell, a single cell RTPCR was performed. The agarose gel shows the co-expression of GFAP and the radial glia cell marker BLPB and the GluA2 subunit of AMPA receptors. The DNA bands were detected at the expected position. A low molecular weight DNA ladder (NEB, Frankfurt, Germany) was used as molecular weight marker. 

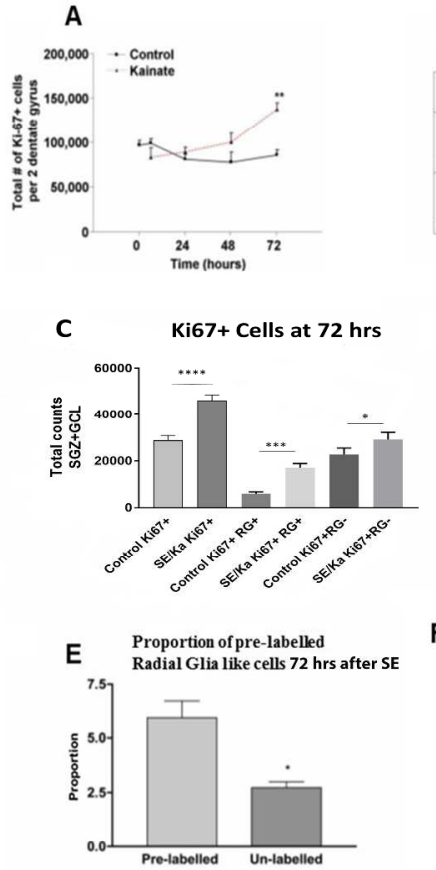

G
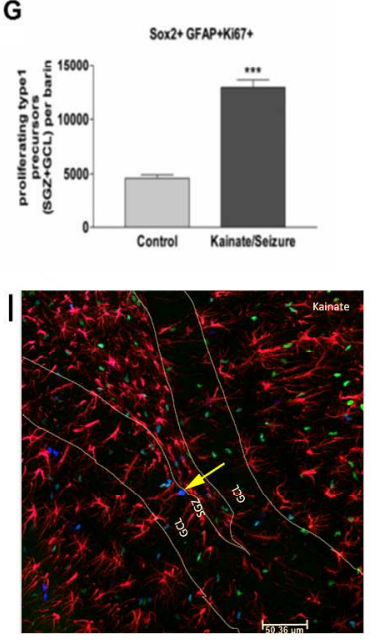

B

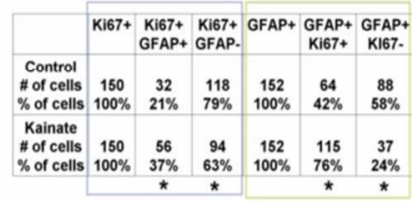

D

$\mathrm{GFAP}+\mathrm{Ki} 67+\mathrm{BrdU}+/ \mathrm{GFAP}+\mathrm{Ki} 67+$
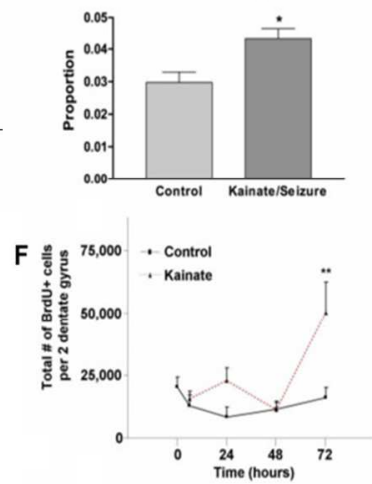

H
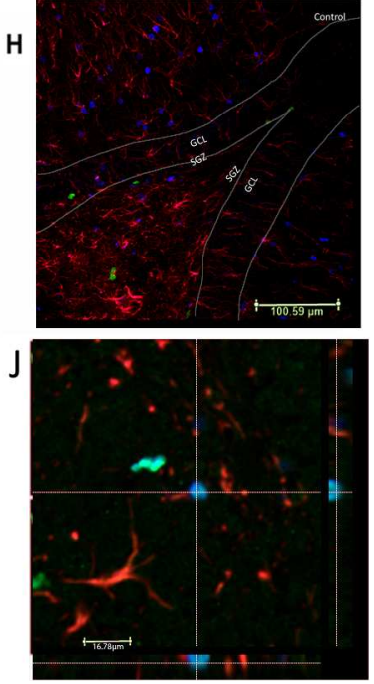

Kainate stimulates proliferation of RG-like cells in the dentate gyrus in-vivo.

\section{PLEASE NOTE}

It did not allow uploading the figure legend (too long)

It's at the end of the main manuscript

\section{$926 \times 1144 \mathrm{~mm}(96 \times 96 \mathrm{DPI})$}




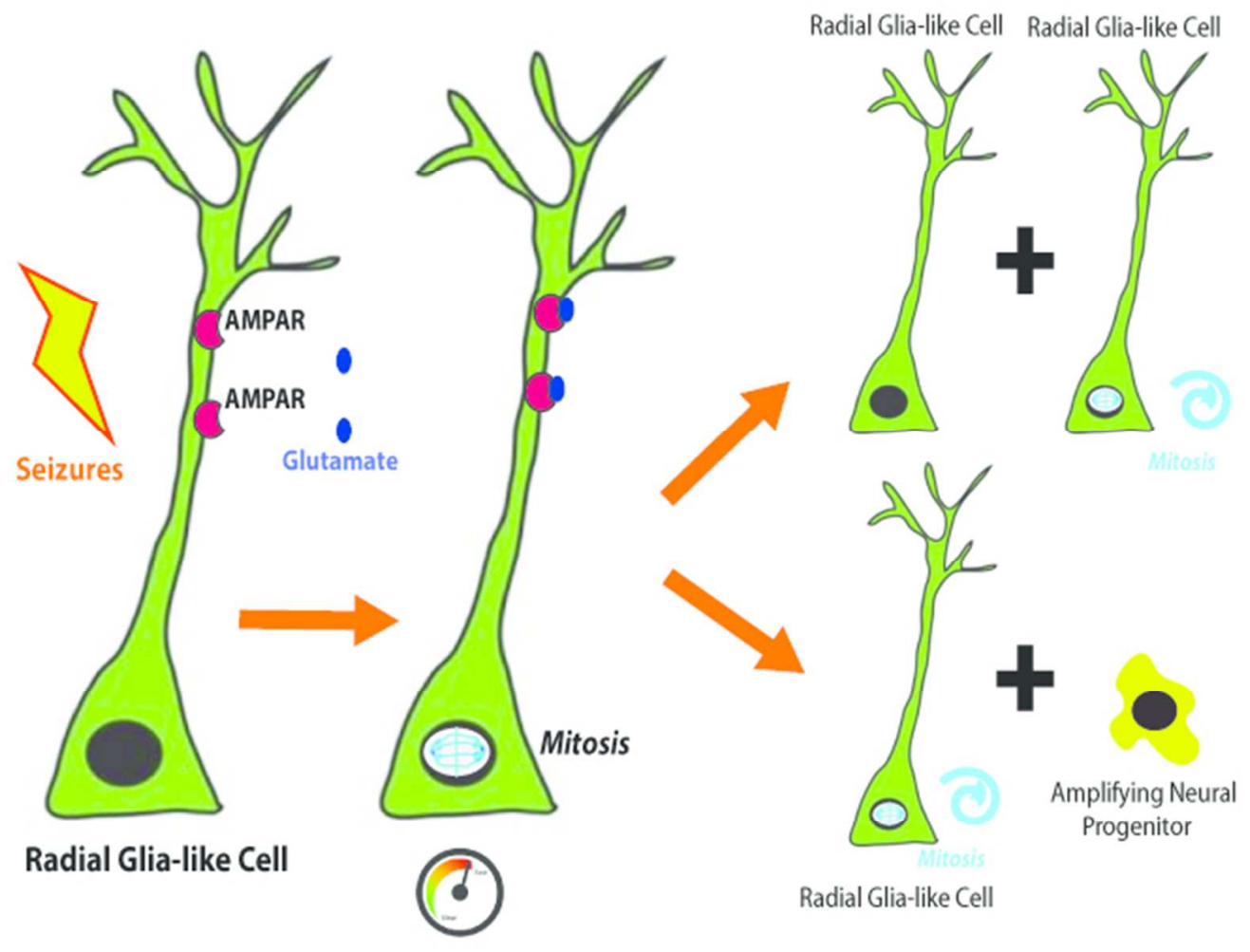

$55 \times 46 \mathrm{~mm}(300 \times 300$ DPI $)$ 